\title{
Balancing cholesterol in the brain: from synthesis to disposal
}

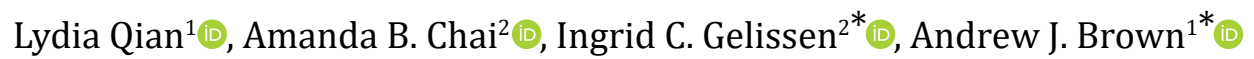 \\ ${ }^{1}$ School of Biotechnology and Biomolecular Sciences, Faculty of Science, University of New South Wales, Sydney, New South \\ Wales 2052, Australia \\ ${ }^{2}$ School of Pharmacy, Faculty of Medicine and Health, University of Sydney, Sydney, New South Wales 2006, Australia
}

${ }^{*}$ Correspondence: Ingrid C. Gelissen, School of Pharmacy, Faculty of Medicine and Health, University of Sydney, Sydney, New South Wales 2006, Australia. ingrid.gelissen@sydney.edu.au; Andrew J. Brown, School of Biotechnology and Biomolecular Sciences, Faculty of Science, University of New South Wales, Sydney, New South Wales 2052, Australia. aj.brown@unsw.edu.au Academic Editor: Ta-Yuan Chang, Geisel School of Medicine at Dartmouth, USA

Received: October 26, 2021 Accepted: December 1, 2021 Published: January 5, 2022

Cite this article: Qian L, Chai AB, Gelissen IC, Brown AJ. Balancing cholesterol in the brain: from synthesis to disposal. Explor Neuroprot Ther. 2022;2:1-27. https://doi.org/10.37349/ent.2022.00015

\begin{abstract}
The cholesterol is a vital component of cell membranes and myelin sheaths, and a precursor for essential molecules such as steroid hormones. In humans, cholesterol is partially obtained through the diet, while the majority is synthesized in the body, primarily in the liver. However, the limited exchange between the central nervous system and peripheral circulation, due to the presence of the blood-brain barrier, necessitates cholesterol in the brain to be exclusively acquired from local de novo synthesis. This cholesterol is reutilized efficiently, rendering a much slower overall turnover of the compound in the brain as compared with the periphery. Furthermore, brain cholesterol is regulated independently from peripheral cholesterol. Numerous enzymes, proteins, and other factors are involved in cholesterol synthesis and metabolism in the brain. Understanding the unique mechanisms and pathways involved in the maintenance of cholesterol homeostasis in the brain is critical, considering perturbations to these processes are implicated in numerous neurodegenerative diseases. This review focuses on the developing understanding of cholesterol metabolism in the brain, discussing the sites and processes involved in its synthesis and regulation, as well as the mechanisms involved in its distribution throughout, and elimination from, the brain.
\end{abstract}

\section{Keywords}

Brain, cholesterol synthesis, cholesterol disposal, oxysterols, ATP-binding cassette transporters, apolipoproteins

\section{Introduction}

Cholesterol plays important structural and functional roles in the brain where it comprises approximately a quarter of the body's total cholesterol pool [1]. It is a crucial molecule for cell membrane formation and flexibility, lipid raft assembly, as well as biochemical processes such as glucose transport and inflammatory signaling [2-4]. In addition, cholesterol can be oxidized into oxysterols, which serve various functions including mediating sterol export [5]. 
Brain cholesterol is acquired and regulated in a different manner to that in peripheral tissues [6]. In the periphery, $70 \%$ of the cholesterol is synthesized de novo in the liver, with the remaining $30 \%$ obtained through dietary intake. This cholesterol pool is subsequently distributed throughout the body via lipoprotein-mediated lipid transfer [7]. However, in the brain negligible cholesterol can be sourced from circulating cholesterol lipoproteins owing to the restrictive nature of the blood-brain barrier and blood-cerebrospinal fluid (CSF) barriers, and so most is synthesized locally within the organ itself [8]. Brain cholesterol accumulates during early development [9], however cholesterol turnover can be very slow in adult brains with a half-life of 0.5 to 5 years compared to just days in circulation $[6,10]$. Brain cholesterol concentration remains relatively constant under normal conditions, with a small fraction replaced via de novo synthesis [11]. However, cholesterol levels may be altered in situations of disease and aging.

Mechanisms are in place to ensure that there is an adequate supply of cholesterol for the functioning of the central nervous system (CNS) and to prevent cholesterol accumulation and associated lipotoxicity [12]. Regulation of cholesterol homeostasis alters during vertebrate development, as the requirements for the sterol for growth and maintenance of various cellular structures may change throughout life. Consequently, cholesterol synthesis and turnover must be tightly regulated to ensure steady levels of sterol in the brain.

Cholesterol biosynthesis is a resource-intensive process as the precursor Acyl-coenzyme A (CoA) is converted into the final sterol by the action of 23 enzymes. The endoplasmic reticulum is the main site for cholesterol synthesis and the location for most of the biosynthetic enzymes. The process can be divided into the early stage, where acetyl-CoA is converted into the first sterol, lanosterol, followed by the post-lanosterol stage which consists of two possible pathways (Figure 1).

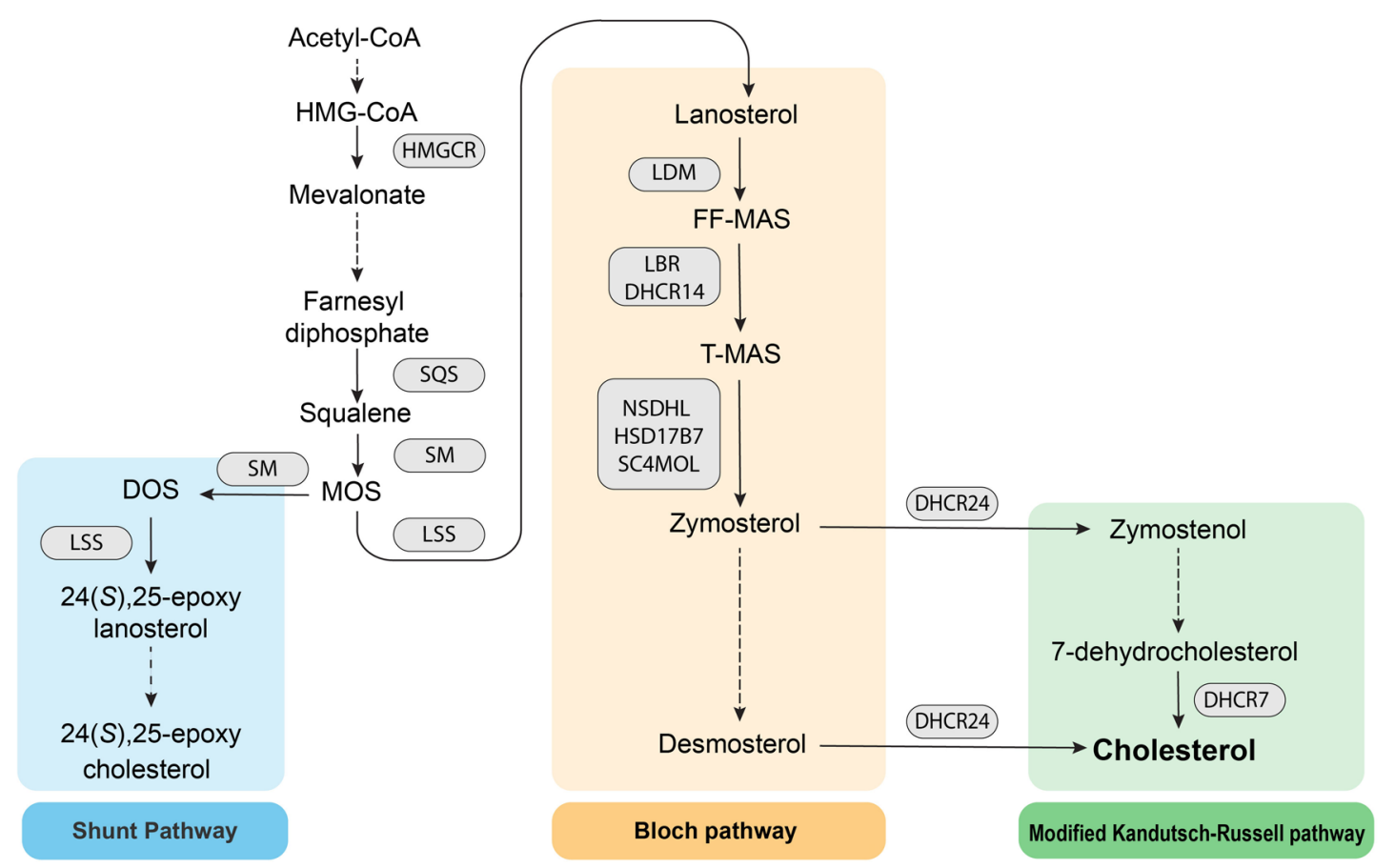

Figure 1. Schematic of the cholesterol biosynthesis pathway. HMG: 3-hydroxy-3-methylglutaryl; SQS: squalene synthase; SM: squalene monooxygenase; MOS: monooxidosqualene; HMGCR: HMG-CoA reductase; LSS: lanosterol synthase; DOS: dioxidosqualene; LDM: lanosterol 14a-demethylase; FF-MAS: follicular fluid meiosis-activating sterol; LBR: lamin B receptor; DHCR14: 14-dehydrocholesterol reductase; T-MAS: testis meiosis-activating sterol; NSDHL: NAD(P) dependent steroid dehydrogenase-like; HSD17B7: hydroxysteroid 17 $\beta$ dehydrogenase 7; SC4MOL: sterol-C4-methyl oxidase like

HMGCR is the first rate-limiting enzyme and the pharmacological target for statins, which are used clinically to lower plasma cholesterol levels. HMGCR catalyzes the reduction of HMG-CoA to mevalonate. Downstream of HMGCR, SQS catalyzes the conversion of farnesyl diphosphate to squalene, the first step specific to sterol biosynthesis. Squalene is subsequently converted into squalene 2,3-epoxide by the second rate-limiting enzyme, SM [13]. Post-lanosterol, sterol intermediates proceed through either the Bloch pathway or the modified Kandutsch-Russell pathway (K-R), which both ultimately yield cholesterol. DHCR24 may act on any intermediate in the Bloch pathway to shuttle intermediates to the modified K-R, 
bypassing upstream and downstream entry points. The partial inhibition of LSS enables accumulation of MOS, which funnels intermediates into the Shunt pathway, in which SM acts a second time on MOS to yield DOS. LSS then catalyzes DOS into 24(S),25-epoxylanosterol which is ultimately converted into $24(S), 25$-epoxycholesterol (24,25-EC).

Feedback regulation of cholesterol synthesis is exquisitely controlled at the transcriptional level by sterol responsive element-binding protein (SREBP) and liver X receptor (LXR) transcription factors $[14,15]$, and at the post-translational level by the ubiquitin-proteasome system [16-19]. Furthermore, several mechanisms operate to remove excess cholesterol from the brain, including intracellular storage, conversion to oxidized metabolites, and efflux into the circulation. Collectively, these mechanisms prevent cholesterol dyshomeostasis within the brain, which can be a key pathological feature in genetic conditions such as Smith-Lemli-Opitz syndrome, as well as neurodegenerative diseases such as multiple sclerosis, Alzheimer's disease, and Parkinson's disease [20-22]. Hence, understanding the metabolism of cholesterol within the brain is crucial for recognizing its significance in the maintenance of brain health and for discerning its role in the pathophysiology of various brain diseases.

In this review, we firstly examine cholesterol synthesis and the preference for the modified Kandutsch-Russell versus the Bloch branches of the cholesterol synthesis pathway in various brain cell subtypes. Secondly, we discuss the cholesterol transport mechanisms and the role of ATP-binding cassette $(\mathrm{ABC})$ transporters in cholesterol distribution. Next, we discuss the transcriptional regulation of cholesterol and its implications for brain health. Finally, we highlight the role of oxysterols in health and disease and the mechanisms for cholesterol clearance from the brain.

\section{Cholesterol synthesis in different brain cell types}

\section{Overview}

The brain contains a diverse population of cells, including neurons and various glial cells-astrocytes, oligodendrocytes, and microglia-each with distinct cholesterol requirements and manufacturing capabilities. Early work with cultured cells derived from animal models indicates that neurons predominantly derive their cholesterol from glial cells. Cultured glial cells from chicken embryos are able to manufacture two- to three-fold more cholesterol than neurons [23], and glial cells transfer cholesterol to other cells via $\mathrm{ABC}$ transporters (discussed in detail below) [24, 25]. In the absence of glial cells, rat neurons synthesize sterols at a lower rate and are unable to compensate for the cholesterol deficit [24]. However, neurons in glial co-cultures drastically downregulate the expression of the early cholesterol biosynthesis pathway enzyme, SQS, suggesting the reduced capacity for cholesterol synthesis $[24,26]$. Neurons in culture rarely esterify newly synthesized cholesterol for storage, and their cholesterol demand is met by exogenous uptake [24, 25].

The brain appears to switch between the use of the post-lanosterol Bloch and K-Rs (summarized in Table 1). Curiously, in developing brains from all mammalian species reported, including humans, desmosterol transiently accumulates to constitute up to $30 \%$ of total brain sterols [27]. The post-translational repression of DHCR24 by progesterone is proposed to cause the desmosterol build-up, to facilitate the enrichment and distribution of membrane sterols in the developing brain [27]. Indeed, sterol profiles of embryonic mice cells indicate desmosterol and other Bloch sterol accumulation in neurons and astrocytes [28]. By contrast, in vitro work showed that post-natal rat neurons accumulate 7-dehydrocholesterol and lathosterol, precursors of the K-R, whilst astrocytes retain Bloch intermediates, namely the immediate cholesterol precursor, desmosterol [24]. Oligodendrocytes and microglia seem to favor the use of the K-R, as these cells derived from post-natal rats have higher proportions of lathosterol and 7-dehydrocholesterol than astrocytes and neurons [24]. Evidently, there is a dynamic exchange in preference for these two pathways within the brain throughout the life of a vertebrate. The characteristics of cholesterol production in brain cells have been studied in specific cell types, with findings summarized in Table 1 and discussed in detail below. 
Table 1. Summary of cholesterol synthesis in brain cell subtypes

\begin{tabular}{|c|c|c|c|c|c|}
\hline Cell type & Subtypes & Function of cell & Function of cholesterol & Cholesterol synthesis & $\begin{array}{l}\text { K-R or Bloch } \\
\text { pathway? }\end{array}$ \\
\hline \multirow[t]{3}{*}{ Neurons } & \multirow[t]{3}{*}{$\begin{array}{l}\text { Subtypes } \\
\text { many* }\end{array}$} & \multirow{3}{*}{$\begin{array}{l}\text { Processing and } \\
\text { transmission of } \\
\text { cellular signals }\end{array}$} & \multirow{2}{*}{$\begin{array}{l}\text { Regulates membrane fluidity, } \\
\text { required for cell membranes } \\
\text { and myelin sheaths [29]. }\end{array}$} & $\begin{array}{l}\text { High during embryonic } \\
\text { development }[28,30] .\end{array}$ & \multirow[t]{3}{*}{ Both $[24,28]$} \\
\hline & & & & \multirow{2}{*}{$\begin{array}{l}\text { Low during adulthood, } \\
\text { when cholesterol is } \\
\text { mainly sourced from } \\
\text { astrocytes }[26,31] .\end{array}$} & \\
\hline & & & $\begin{array}{l}\text { Present in lipid rafts and } \\
\text { facilitates ion channel function, } \\
\text { neuron receptor localization, } \\
\text { neurotransmitter transport, } \\
\text { and cellular growth and } \\
\text { development }[2,26,29] .\end{array}$ & & \\
\hline \multirow[t]{7}{*}{ Glial cells } & \multirow[t]{3}{*}{ Astrocytes } & \multirow{3}{*}{$\begin{array}{l}\text { Maintenance of } \\
\text { CNS homeostasis, } \\
\text { provision of } \\
\text { biochemical and } \\
\text { nutritional support to } \\
\text { neurons and blood- } \\
\text { brain barrier, synaptic } \\
\text { transmission, immune } \\
\text { function }\end{array}$} & \multirow{2}{*}{$\begin{array}{l}\text { Required for cell membrane } \\
\text { fluidity regulation, lipid raft } \\
\text { formation, and carbohydrate } \\
\text { metabolism [32]. }\end{array}$} & $\begin{array}{l}\text { Low during embryonic } \\
\text { development [28]. }\end{array}$ & \multirow[t]{3}{*}{ Bloch [24] } \\
\hline & & & & \multirow[t]{2}{*}{ High after birth $[26,34]}$. & \\
\hline & & & $\begin{array}{l}\text { Cholesterol is exported to other } \\
\text { brain cells }[32,33] \text {. }\end{array}$ & & \\
\hline & \multirow[t]{2}{*}{$\begin{array}{l}\text { Oligodendro- } \\
\text { cytes }\end{array}$} & \multirow{2}{*}{$\begin{array}{l}\text { Synthesis and } \\
\text { maintenance of } \\
\text { myelin sheaths to } \\
\text { insulate neuronal } \\
\text { axons for faster signal } \\
\text { transmission }\end{array}$} & \multirow[t]{2}{*}{$\begin{array}{l}\text { Required for synthesis of myelin } \\
\text { sheaths [35-37]. }\end{array}$} & $\begin{array}{l}\text { High after birth and in } \\
\text { early childhood }[9,35] \text {. }\end{array}$ & \multirow{2}{*}{$\begin{array}{l}\text { Possibly } \\
\text { K-R [24] but } \\
\text { requires further } \\
\text { study }\end{array}$} \\
\hline & & & & $\begin{array}{l}\text { Dynamic during } \\
\text { adulthood. Cholesterol } \\
\text { is sourced locally and } \\
\text { from astrocytes }[38,39] .\end{array}$ & \\
\hline & \multirow[t]{2}{*}{ Microglia } & \multirow[t]{2}{*}{$\begin{array}{l}\text { Brain macrophage; } \\
\text { immune function and } \\
\text { injury repair }\end{array}$} & $\begin{array}{l}\text { Lipid composition modulates } \\
\text { microglial function in } \\
\text { phagocytosis, immune } \\
\text { surveying, synapse } \\
\text { pruning }[33,40,41] .\end{array}$ & \multirow[t]{2}{*}{$\begin{array}{l}\text { Synthesis rate low, } \\
\text { sourced from astrocytes } \\
\text { [43]. }\end{array}$} & \multirow[t]{2}{*}{$\begin{array}{l}\text { Possibly } \\
\text { K-R [24] but } \\
\text { requires further } \\
\text { study }\end{array}$} \\
\hline & & & $\begin{array}{l}\text { Desmosterol (cholesterol } \\
\text { precursor) activates } \\
\text { LXR signaling to resolve } \\
\text { inflammation and promote } \\
\text { oligodendrocyte maturation [42]. }\end{array}$ & & \\
\hline
\end{tabular}

* Note that many neuronal subtypes are present in the brain, but for the purpose of this review the main role of neurons and their cholesterol synthesis is discussed

\section{Neurons}

In neurons, cholesterol is an important component of myelin and the membranes of synapses, dendrites, and axons, where it regulates membrane fluidity [29]. Neurons can synthesize their own cholesterol to a limited extent. Murine neurons express mRNA transcripts and proteins of components of the cholesterol synthesis pathway, including those for the early enzyme SQS, the post-lanosterol enzymes NSDHL and LDM, and the terminal enzyme DHCR24 [24, 42]. Neuron-rich areas of the mouse hippocampus express higher amounts of cholesterol biosynthetic enzyme mRNA transcripts than astrocyte-rich areas [44], although this may not translate to protein expression or enzyme activity.

The ability of neurons to produce cholesterol is dependent on the life stage of the vertebrate. Developing neurons actively and locally synthesize cholesterol with the endogenous sterol pool increasing over time [28]. A comparison of cholesterol synthesis in neurons between adult versus embryonic mice reveals striking differences. Adult mice with a neuron-specific cholesterol synthesis ablation due to a deletion of SQS, are phenotypically similar to wild-type mice, indicating that neurons in adults do not contribute to the overall cholesterol synthesis in the brain [31]. However, ablation of cholesterol synthesis via conditional SQS knockout in murine neuronal precursor cells is perinatally lethal, with embryos developing smaller brains [30]. Neurons compensate by promoting angiogenesis to increase lipoprotein uptake [30]. Together, these studies indicate that cholesterol synthesis predominantly occurs in neuron precursor cells or neurons during early development. 


\section{Astrocytes}

Astrocytes are thought to be the main hubs for cholesterol synthesis in the brain, with most of the sterol supplied to neurons [45]. These glial cells support neuronal growth and development during childhood, and neuronal maintenance throughout adulthood [32]. Cholesterol is synthesized in the endoplasmic reticulum and rapidly transported to the plasma membrane in vesicles and via apolipoprotein-mediated systems [32]. During development, astrocytes maintain strict control of their endogenous cholesterol homeostasis [28].

Several lines of evidence support the idea that astrocytes are the main cholesterol manufacturers in the brain. Murine studies have shown that transcriptional control of cholesterol biosynthesis is more prevalent in astrocytes as SREBP-1 is more highly expressed in the astrocytes compared to neurons [26]. In addition, between murine astrocytes, oligodendrocytes, and microglia, astrocytes express the highest levels of transcripts of the cholesterol synthesis enzymes throughout the entire biosynthetic pathway [42].

The importance of astrocyte cholesterol synthesis in the brain is underscored by the dramatic phenotypic changes observed when the process is disrupted in murine models. The complete inactivation of the murine equivalents of HMG-CoA reductase and SQS, HMGCR, and SQS, via mutational gene disruptions is embryonically lethal $[46,47]$. Conditional mutations of Sqs are not lethal to mice but result in many neurological defects. Mice with astrocyte-specific SQS mutations have a limited ability to secrete cholesterol from astrocytes. In addition, neuronal synapses and synaptic vesicles are unable to mature, suggesting that neurons are dependent on astrocyte-derived cholesterol to support the formation of synapses [26]. Evidently, cholesterol sourced from astrocytes is critical for neuronal function.

\section{Oligodendrocytes}

Oligodendrocytes wrap axons with cholesterol-rich myelin, providing the electrical insulation necessary for a process called saltatory conduction. Electrical impulses can also skip between nodes of the axon not insulated by myelin, speeding up the arrival of the signal to the synaptic terminal [36]. Oligodendrocytes synthesize substantial amounts of cholesterol for myelin formation and maintenance. Like astrocytes, murine oligodendrocytes express high levels of cholesterogenic transcripts, especially those for the post-lanosterol enzymes, LDM, and DHCR24 [42]. Cholesterol in oligodendrocytes is synthesized de novo via a feed-forward process involving phosphoinositide 3-kinase/protein kinase B/mammalian target of rapamycin (PI3K/Akt/mTOR) signaling [48].

Myelin contains a large proportion of the brain's cholesterol store, with estimates from murine models indicating that $80 \%$ of the brain's cholesterol resides within myelin [35]. Rodent studies indicate that the timing of myelination correlates with total brain cholesterol accumulation during the first three weeks of life $[9,35]$. Nevertheless, myelination and oligodendrocyte maturation continue during the adult life stages of a mammal [37].

A disruption in oligodendrocyte cholesterol synthesis reduces the rate of CNS myelination and perturbs motor function and coordination [38]. Cholesterol-deficient oligodendrocytes can compensate through cholesterol uptake from neighboring cells [38]. Cholesterol availability is a limiting factor of myelin growth during development, with cholesterol synthesis in oligodendrocytes especially crucial during early life stages. Myelination continues throughout adulthood for the growth and repair of white matter tissue [37]. The regulation of this process is dynamic and cholesterol crosstalk occurs between astrocytes and oligodendrocytes. An in vitro study indicates that astrocytes from grey matter (an area of the brain rich in neuronal bodies) rather than white matter (an area in the brain rich in myelinated axons) are able to secrete cholesterol and support myelination [39]. Clearly, when cholesterol supply is disrupted, astrocytes are a critical source of cholesterol necessary for myelination. Further studies are warranted to explore how cells can re-route neural circuits during myelin repair and what signaling processes are involved. Such studies may offer novel insights into the pathophysiology of neurological diseases such as multiple sclerosis, which is characterized by immune-mediated demyelination and loss of axons [49]. 


\section{Microglia}

Microglia are phagocytic immune cells in the CNS that engulf lipid debris and trigger apoptosis. Microglia survey and respond to the state of synapses, in a process known as synaptic pruning, which is particularly active in the developing brain [41]. A sub-population of microglia is responsible for the removal of myelin debris and remyelination [40]. Microglia adapt and respond to many environmental cues, such as neuroinflammation in diseases such as Alzheimer's disease, Parkinson's disease, and multiple sclerosis. Cellular lipid composition influences microglial function $[33,40]$; while cholesterol is essential for microglial survival [43], excessive intracellular cholesterol accumulation in aged or pro-inflammatory microglia in multiple sclerosis is toxic and impairs the ability for microglia to phagocytose myelin debris and repair myelin [50, 51].

Microglia do not synthesize large amounts of cholesterol since cholesterogenic enzymes in murine microglia exhibit a low transcription profile compared to other glial cells [42]. Instead, microglia derive most of their cholesterol from neighboring astrocytes [43]. However, the synthesis of cholesterol intermediates is more critical in microglia. A recent study found that desmosterol, the immediate cholesterol precursor in the Bloch pathway, is critical for the repair of demyelinated lesions [42]. Desmosterol activates LXR signaling for cholesterol efflux to resolve inflammation and promote oligodendrocyte differentiation [42]. The synthesis of other sterol intermediates could also play a role in microglia function; however, this requires further investigation.

\section{Cholesterol transport in the brain}

Transport of cholesterol in the brain is largely contained within the organ itself due to limitations in cholesterol trafficking across the blood-brain barrier. Brain cell types have various mechanisms available to export and/or accept cholesterol from other cells (summarized in Figure 2). Astrocytes are thought to be the primary cholesterol exporters, with the sterol bound to apolipoproteins in high-density lipoprotein (HDL)like particles [52]. The two main apolipoproteins for cholesterol transport in the brain are apolipoprotein E (ApoE) and ApoJ, also known as clusterin [53]. The apolipoproteins can bind to a variety of receptors for cholesterol uptake into cells, including low-density lipoprotein (LDL) receptor (LDLR), LDLR-related protein 1 (LRP1), and triggering receptor expressed on myeloid cells 2 (TREM2) [20, 53]. As aforementioned, other brain cells often require the utilization of astrocyte-derived cholesterol. Receipt of cholesterol from astrocytes by cholesterol-deficient oligodendrocytes in mice is likely mediated by ApoE and its receptor LRP1 [36, 54]. Microglia cultured in vitro requires ApoE and clusterin-containing lipoproteins for survival and phagocytosis [43]. Lipidated ApoE and/or clusterin efficiently bind to the TREM2 receptor [55] expressed by microglia. Murine neurons in culture require ApoE-bound cholesterol sourced from glial cells to induce synaptogenesis $[52,56]$. Astrocytes are proposed to release lipids such as cholesterol for direct insertion into neuronal membranes to influence synaptic transmission, although further studies into the lipid-metabolizing enzymes and lipid trafficking mechanisms in glial cells are needed [33]. Neurons can release cholesterol bound to apolipoproteins [52] or in the oxidized form as 24(S)-hydroxycholesterol (24S-HC) [57].

The variety and brain-cell type-specific distribution of cholesterol trafficking-related proteins, and the difficulty of in situ observations, complicate the in vivo characterization of physiological brain cholesterol transport. ApoE and clusterin have been studied to varying extents and their structure, function, cell-type-specific expressions, and roles in the context of Alzheimer's disease are discussed below.

Cholesterol is trafficked in the brain in association with ApoE or clusterin in HDL-like particles. Astrocytes are the primary source of cholesterol synthesis and transport in the brain. Astrocytes transport lipidated ApoE-containing lipoproteins to neurons. Neurons express clusterin and excess cholesterol from neurons is converted into 24S-HC by cytochrome P450 (CYP) 46A1 (CYP46A1) for efflux. Oligodendrocytes synthesize large amounts of cholesterol for myelination and may take up additional cholesterol from astrocytes. Microglia encounter HDL-like lipoproteins from astrocytes and take up the cholesterol via the receptors, TREM2 and LDLR. A minor proportion of cholesterol can be exported out of the brain in ApoE-containing lipoproteins. However, most of the excess cholesterol is converted into $24 S$-HC, which 
diffuses across the blood-brain barrier into the periphery. 27-HC synthesized by peripheral cells may cross the blood-brain barrier into the brain and act as an indicator of plasma cholesterol levels in the brain. The well-studied cholesterol exporters, ABCA1, ABCG1, and ABCG4 are expressed by astrocytes, neurons, and microglia. ABCA1 and ABCG1 are expressed by oligodendrocytes.

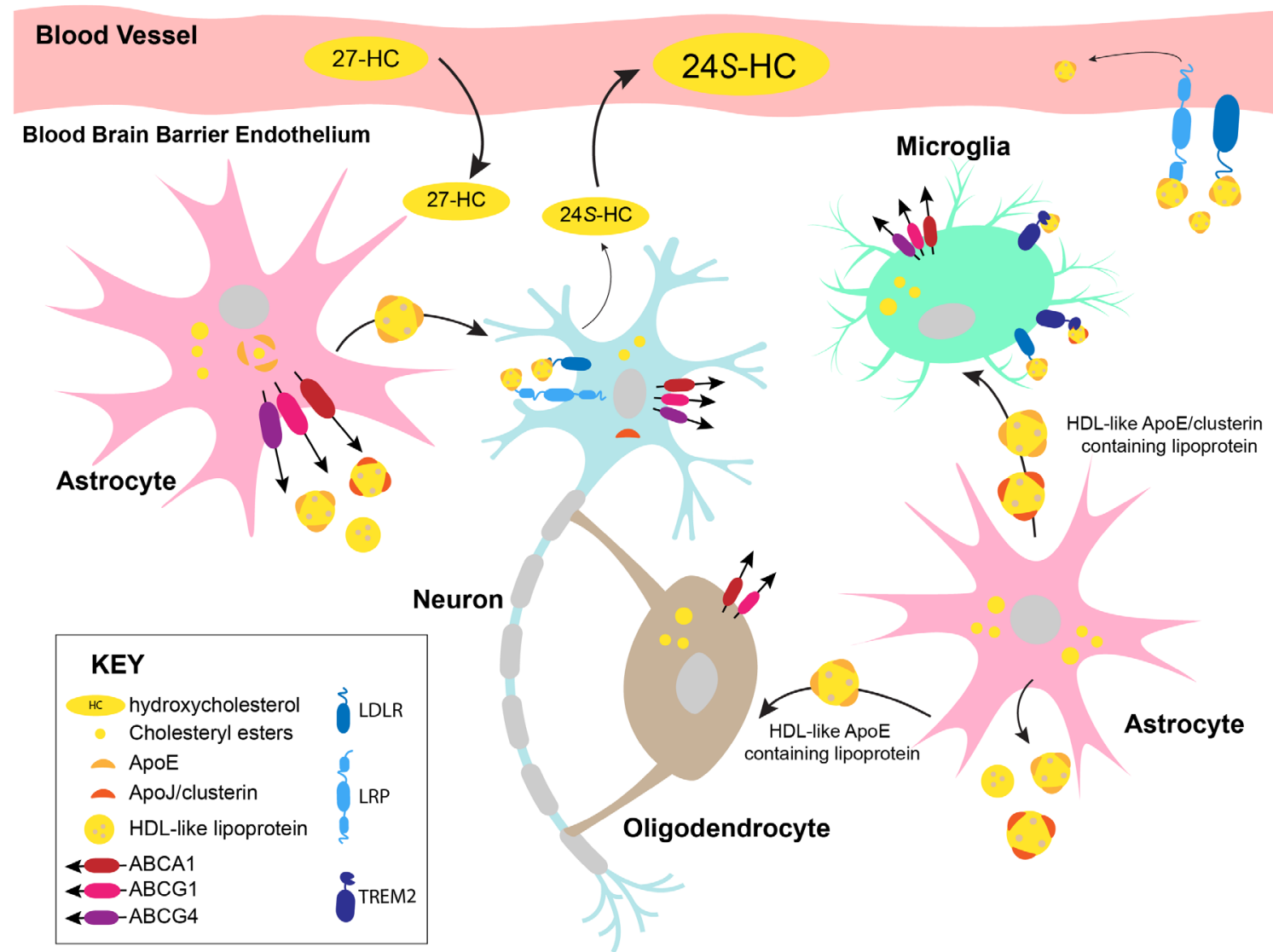

Figure 2. Cholesterol trafficking in the brain. 27-HC: 27-hydroxycholesterol; $A B C A 1$ : $A B C$ transporter subfamily $A$ member 1; ABCG1: ABC transporter subfamily $G$ member 1

\section{Apolipoproteins: ApoE and clusterin}

ApoE is the most abundant lipoprotein in the CNS and is synthesized locally chiefly by astrocytes, partially by microglia, and minimally by neurons [58]. ApoE oligomers cannot be complex with lipids. However, upon monomerization, the lipid-binding region is exposed and the protein is able to bind lipids [59-62]. Lipidation of ApoE by cholesterol and phospholipids is mediated by ABC transporters. The resultant HDL-like particles are then secreted by astrocytes into the interstitial fluid [15]. Fully lipidated ApoE undergoes a conformational change to enable interaction with its receptors for cellular uptake [63].

Clusterin is the second major apolipoprotein present in the brain [64]. It is a multifunctional glycoprotein that is distributed in lipoproteins and ubiquitously expressed in the extracellular matrix of many tissues throughout the body and in the CNS $[53,65]$. The protein consists of two linked polypeptide chains, which can be configured into different proteoforms by the presence or absence of glycosylation [66]. The proteoform structure confers specificity in the protein's subcellular localization and function [66]. Intracellular clusterin regulates apoptosis $[67,68]$ and mitochondrial function $[69,70]$ and is not known to transport cholesterol. Only the most mature and glycosylated form of clusterin is secreted from the cell and is a known component of circulating peripheral lipoproteins and HDL-like particles in the brain [71]. Clusterin is expressed by both astrocytes and neurons [72], as well as the ependymal cells lining the ventricle [72, 73]. Clusterin is required for lipid trafficking [74] and is able to bind to the LRP2 receptor in vitro [75], with lipidated clusterin enhancing the binding affinity [65]. The interplay between the role of clusterin as a cholesterol carrier and its intracellular functions is an avenue for further exploration. 
Other lipoproteins present in the brain, albeit in smaller quantities, include the peripherally-derived apolipoproteins ApoA-I and ApoA-II, and ApoD, ApoC-I, ApoA-IV, and ApoH which are synthesized within the brain. Their roles in cholesterol transport within the CNS are poorly understood [76, 77].

\section{Cholesterol trafficking genes are implicated in late-onset Alzheimer's disease}

Three major isoforms exist for ApoE in humans, ApoE2, ApoE3, and ApoE4. The ApoE4 isoform, as well as a single nucleotide polymorphism (SNP) in the clusterin gene (CLU) are associated with elevated risk for Alzheimer's disease $[64,78,79]$, suggesting that cholesterol trafficking may be dysregulated in patients with the disease. Indeed, cholesterol abnormalities have been observed in these patients; plasma membranes of brain cells are enriched with cholesterol, and these cholesterol levels persistently increase throughout the course of the disease $[80,81]$.

The ApoE4 isoform correlates with impaired clearance of amyloid-beta (A $\beta$ ) peptides [82], which are a characteristic feature of the Alzheimer's brain and have been shown to contribute to neurotoxicity and neurodegeneration [79]. The ApoE4 isoform does not operate as efficiently in the delivery of cholesterol to neurons as compared with the ApoE3 isoform [72]. ApoE isoform-dependent processing of $A \beta$ has been recently reviewed by Chai et al [82]. In addition to its role as a cholesterol carrier, secreted clusterin may serve as a protein chaperone outside the cell, in a similar manner to heat shock proteins [83]. Clusterin can be complex with A $\beta$ to mediate endocytosis and transcytosis [84] and is thought to promote cell survival [64]. An Alzheimer's disease-associated SNP in clusterin affects the alternative splicing of the gene, decreases its expression, and likely reduces $A \beta$ clearance [64]. Cholesterol and $A \beta$ aggregate carried by ApoE and/or clusterin bind with the microglial receptor, TREM2, in human cells cultured in vitro [55], suggesting that cholesterol and $\mathrm{A} \beta$ aggregates can be cleared by microglia.

The precise molecular mechanisms of how the different ApoE isoforms and clusterin transport cholesterol in healthy brains versus in Alzheimer's disease still require further examination. The lipid and apolipoprotein composition of extracellular vesicles from healthy and diseased brains could be analyzed by comprehensive 'omic' studies [85]. These vesicles are reflective of intracellular contents, providing a non-invasive method of study. Proteomic and lipidomic studies can be coupled with reductionist approaches with in vivo models to understand the nuances of apolipoprotein-mediated cholesterol transport in healthy versus diseased brains. Further elucidation of structural and conformational changes of ApoE and clusterin upon cholesterol-binding is not only important for understanding cholesterol transport in the brain but may also facilitate future drug target design for Alzheimer's disease.

\section{Transport of brain cholesterol by ABC transporters}

The distribution of cholesterol and other lipids within the brain is facilitated by the actions of $\mathrm{ABC}$ transporters. These transporters are widely expressed throughout the body and utilize the energy generated from ATP hydrolysis to translocate a broad variety of endogenous and exogenous substrates across cell membranes. In humans, the $\mathrm{ABC}$ transporter superfamily encompasses 48 structurally similar proteins categorized into seven families designated ABCA to ABCG. The majority of these are full transporters, exhibiting a four-domain composition consisting of two cytoplasmic nucleotide-binding domains (which house the signature LSGGQ amino acid motif) and two transmembrane domains (which dictate the ligand specificity) [86]. Half transporters, such as ABCDs and ABCGs, contain a single nucleotide-binding domain and a single transmembrane domain and must form homo- or hetero-dimers to be fully functional. Several $\mathrm{ABC}$ transporters that are expressed in the brain are also known to transport lipid substrates (Table 2). While many of these have only been investigated with respect to their lipid-transporting capacity in the periphery

and thus whether corresponding functions exist for them in the brain remain unexplored, important roles have been identified for ABCA1, ABCG1, and ABCG4 in brain cholesterol transport. 
Table 2. ABC lipid transporters expressed in the brain

\begin{tabular}{|c|c|c|c|c|c|c|c|c|c|}
\hline \multirow{2}{*}{$\begin{array}{l}\mathrm{ABC} \\
\text { subfamily }\end{array}$} & \multirow{2}{*}{$\begin{array}{l}\text { Trans- } \\
\text { porter }\end{array}$} & \multicolumn{7}{|c|}{ Cellular location within the brain } & \multirow{2}{*}{$\begin{array}{l}\text { Lipid substrates } \\
\text { (including brain and } \\
\text { periphery) }\end{array}$} \\
\hline & & Neurons & $\begin{array}{l}\text { Astro- } \\
\text { cytes }\end{array}$ & $\begin{array}{l}\text { Oligo- } \\
\text { dendro- } \\
\text { cytes }\end{array}$ & Microglia & $\begin{array}{l}\text { Choroid } \\
\text { plexus } \\
\text { epithelial } \\
\text { cells }\end{array}$ & $\begin{array}{l}\text { Capillary } \\
\text { endothelial } \\
\text { cells }\end{array}$ & References & \\
\hline \multirow[t]{5}{*}{$A B C A$} & ABCA1 & • & • & • & • & • & • & $\begin{array}{l}{[87-89,90-} \\
92]\end{array}$ & $\begin{array}{l}\text { Cholesterol, phospholipids } \\
\text { (PC, PS), oxysterols (24S-HC) } \\
\text { [93-95] }\end{array}$ \\
\hline & $\mathrm{ABCA} 2$ & • & • & • & - & - & • & $\begin{array}{l}{[87-89,91} \\
92,96]\end{array}$ & $\begin{array}{l}\text { Cholesterol, sphingomyelin, } \\
\text { glycosphingolipids [97-99] }\end{array}$ \\
\hline & ABCA3 & - & - & • & - & - & • & $\begin{array}{l}{[87,89,92,} \\
96]\end{array}$ & $\begin{array}{l}\text { Possibly cholesterol, } \\
\text { phospholipids (PC, PG) [89, } \\
\text { 100-102] }\end{array}$ \\
\hline & $\mathrm{ABCA} 7$ & - & - & • & • & - & - & {$[87,89]$} & $\begin{array}{l}\text { Possibly cholesterol, } \\
\text { phospholipids (PC, } \\
\text { sphingomyelin) [103-105] }\end{array}$ \\
\hline & ABCA8 & • & - & - & • & - & - & {$[87,89,106]$} & | Cholesterol [107] \\
\hline$A B C B$ & ABCB1 & • & • & - & - & - & • & $\begin{array}{l}{[89,91,96,} \\
108-110]\end{array}$ & $\begin{array}{l}\text { Possibly cholesterol, } \\
\text { phospholipids (PC, PE, } \\
\text { PS, sphingomyelin), } \\
\text { glucosylceramide, } \\
\text { glycosphingolipids [111-115] }\end{array}$ \\
\hline$A B C C$ & ABCC6 & • & - & - & - & - & • & {$[91,116]$} & $\begin{array}{l}\text { Associated with plasma } \\
\text { lipoprotein and HDL levels } \\
\text { [117] }\end{array}$ \\
\hline \multirow[t]{3}{*}{$A B C D$} & ABCD1 & - & • & • & • & - & • & {$[89,91]$} & $\begin{array}{l}\text { Very long-chain fatty acids } \\
\text { (preference for saturated } \\
\text { species), fatty acyl-CoAs [118, } \\
119]\end{array}$ \\
\hline & ABCD2 & • & - & - & - & - & - & {$[89,118]$} & $\begin{array}{l}\text { Very long-chain fatty } \\
\text { acids (preference for } \\
\text { polyunsaturated species), fatty } \\
\text { acyl-CoAs }[118,119]\end{array}$ \\
\hline & ABCD3 & - & - & - & - & - & • & [96] & $\begin{array}{l}\text { Very long-chain fatty acids, } \\
\text { long and branched-chain } \\
\text { acyl-CoA }[118,119]\end{array}$ \\
\hline \multirow[t]{2}{*}{$A B C G$} & ABCG1 & • & • & • & • & $\cdot$ & $\cdot$ & $\begin{array}{l}{[88-91,120,} \\
121]\end{array}$ & $\begin{array}{l}\text { Cholesterol, phospholipids } \\
\text { (PC), oxysterols, desmosterol } \\
{[88,93,120,122,123]}\end{array}$ \\
\hline & ABCG4 & • & • & - & • & - & • & $\begin{array}{l}{[89,91,120,} \\
124]\end{array}$ & $\begin{array}{l}\text { Cholesterol, cholesterol } \\
\text { synthesis intermediates } \\
\text { (desmosterol, lathosterol, } \\
\text { lanosterol), oxysterols [120, } \\
125-127]\end{array}$ \\
\hline
\end{tabular}

Note that the substrates listed here are not limited to the brain and may reflect data from systemic studies since investigations regarding the cholesterol/lipid-transporting activity of ABC transporters within the brain are still limited. "." denotes expression has been observed in the cell line, "-" indicates no expression or no data. PC: phosphatidylcholine; PE: phosphatidylethanolamine; PG: phosphatidylglycerol; PS: phosphatidylserine; $A B C B$ : $A B C$ transporter subfamily $B ; A B C C$ : $A B C$ transporter subfamily $C$

\section{ABCA1 and ABCG1}

The two most extensively studied ABC transporters involved in lipid transport in the CNS are ABCA1 and ABCG1. Both transporters are highly expressed in the brain, including in neurons, microglia, astrocytes, and oligodendrocytes [87]. ABCA1 mediates the initial transfer of cholesterol and phospholipids to lipid-free or poorly-lipidated ApoE and ApoA-I, to form nascent discoidal HDL-like particles. This is followed by further lipidation by ABCG1 (or ABCG4), which interacts preferentially with partially lipidated species $[93,128]$. This process has been demonstrated to occur in neurons [88], as well as astrocytes and microglia [129, 130]. The resultant lipoproteins may undergo further remodeling by enzymes and lipid transfer proteins to yield mature HDL-like particles that distribute cholesterol around the CNS [131]. 
Whilst the absence of ABCG1 in mice has minimal effect on brain cholesterol levels [120], ABCA1 deficiency leads to significant cholesterol dyshomeostasis in the murine brain, resulting in structural and functional disturbances to neurons. In the absence of ABCA1, brain cholesterol content is reduced, and cholesterol export from glial cells is impaired, limiting its availability for utilization by neurons. These alterations to brain cholesterol metabolism elicit compensational enhancement of brain uptake of esterified cholesterol from plasma HDL [132]. Abca1-null mice also have lower levels of ApoE in the CNS, with the ApoE particles tending to be smaller and poorly lipidated $[129,133]$.

\section{ABCA family (ABCA2/ABCA3/ABCA7/ABCA8)}

Expression of $\mathrm{ABCA2}$ is higher in the brain compared to other tissues and is predominantly found intracellularly, rather than on the cell surface, within lysosomes of oligodendrocytes and to a lesser extent in neurons [89]. Corresponding with the role of oligodendrocytes in myelin formation, ABCA2 has been implicated in the metabolism of myelin lipids, including sphingomyelin and gangliosides [97, 134]. The effect of ABCA2 on cholesterol homeostasis is controversial. ABCA2 deficiency leads to cholesterol accumulation in macrophages [98], and overexpression of ABCA2 in N2a neuroblastoma cells is associated with reduced total, free and esterified cholesterol levels and reduced cholesterol efflux to ApoE3 [99]. However, overexpression of ABCA2 in HEK293 cells had no effect on cholesterol efflux to ApoA-I, ApoE, or ApoE discs [88].

ABCA3 is primarily expressed on the limiting membrane of lamellar bodies of lung alveolar type II (ATII) cells, where it serves a critical role in the formation of pulmonary surfactant by trafficking PC and PG into the lamellar bodies for storage $[89,100]$. Its role in cholesterol and sphingomyelin transport is controversial. The levels of these lipids were unaffected by deletion of the transporter in the murine lung [101], whereas the silencing of ABCA3 expression in human ATII cells reduced sphingomyelin and cholesterol uptake into lamellar bodies [102]. The function of ABCA3 in the brain, including oligodendrocytes where expression is highest [89], remains unexplored.

ABCA7 exhibits the greatest sequence homology with ABCA1 (54\%). Its expression in the brain is highest in microglia [89]. Human ABCA7 exhibits two isoforms, type I and type II, which arise from alternative gene splicing. These isoforms have consequently been shown to exhibit varying capabilities in transporting cholesterol and phospholipid to ApoA-I [103]. A separate study found that ABCA7 could mediate phospholipid efflux (including PC and sphingomyelin) to ApoA-I, but that its role in cholesterol efflux was limited [104]. ABCA7-mediated cholesterol efflux has been demonstrated to occur to ApoE discs, but not lipid-free ApoE [105]. The $A B C A 7$ gene has been identified in genome-wide association studies as a risk factor for Alzheimer's disease [135]. Although its exact contribution to pathogenesis remains to be determined, it has been proposed that lipid transport by ABCA7 serves a protective effect [136], with low ABCA7 expression correlating with increased disease risk and poorer prognosis $[135,137,138]$.

ABCA8 promotes cholesterol efflux to ApoA-I in the periphery and increases plasma HDL-cholesterol levels, therefore exhibiting some functional overlap with ABCA1 [107]. Although it does not transport sphingomyelin, ABCA8 has been shown to promote sphingomyelin synthesis in oligodendrocytes, thereby implicating a role in myelin formation and maintenance [139].

\section{ABCB family (ABCB1)}

ABCB1 exports a large profile of structurally and chemically unrelated substrates, the most notable category of which includes therapeutic drugs. ABCB1 has additionally been recognized as a lipid transporter, with in vitro studies utilizing LLC-PK1 pig kidney epithelial cells transfected with human ABCB1 and human gastric carcinoma cells overexpressing $\mathrm{ABCB} 1$ demonstrating that the transporter promotes the efflux of phospholipids, glucosylceramide and sphingomyelin [111,112]. The ability of ABCB1 to transport cholesterol, however, remains controversial [113, 114]. The role of CNS-expressed ABCB1 in transporting lipid substrates has not yet been assessed, but it appears plausible based on existing data that have focused on its activity in the periphery. 


\section{ABCC family (ABCC6)}

Despite its expression in neurons and capillary endothelial cells in the brain [116], the present understanding of the physiological function of ABCC6 remains limited to the periphery. Mutations to the gene encoding ABCC6 may give rise to the autosomal recessive disorder, pseudoxanthoma elasticum (PXE), which is characterized by atherogenesis and calcification of connective tissues in the body. PXE patients and Abcc6-deficient mice exhibit reduced ApoE, ApoA-I, ApoA-II, and HDL-cholesterol levels, and enhanced cholesterol biosynthesis activity [140,141], implicating a role for ABCC6 in maintaining cholesterol homeostasis.

\section{ABCD family (ABCD1/ABCD2/ABCD3)}

ABCD1-3 is expressed at the peroxisomal membranes of glial cells, neurons, and capillary endothelial cells, where they transport fatty acids into the peroxisome for metabolism [89]. The importance of ABCD1 activity for lipid homeostasis is highlighted by the recognition that mutations to the $A B C D 1$ gene result in X-linked adrenoleukodystrophy, a severe neurological disorder characterized by progressive demyelination of the CNS. These patients exhibit accumulation of very long-chain fatty acids in the brain due to impaired ABCD1-mediated peroxisomal uptake for subsequent oxidation [118].

\section{ABCG family (ABCG4)}

ABCG4 expression in humans is limited to the brain. ABCG4 exhibits 74\% amino acid homology with ABCG1, thus exhibiting overlapping functionality in promoting cholesterol efflux to HDL [89, 93, 125]. ABCG1 and ABCG4 may also be co-expressed and form heterodimers, to facilitate the efflux of oxysterols (24S-HC, 27-HC) and sterol intermediates (desmosterol, lathosterol, lanosterol) from astrocytes to HDL [120, 126, 142, 143].

\section{Transcriptional regulation of cholesterol in the brain}

Cholesterol metabolism is regulated by two transcriptional axes; the SREBP transcription factors and the LXR and retinoid X receptor (RXR) transcription factors. The genes responsible for cholesterol synthesis are upregulated by SREBP-1a and SREBP-2 [144]. Components of the SREBP pathway are widely expressed across all tissues, including in the brain [17]. SREBP transcription factors reside within the endoplasmic reticulum, where it is bound to SREBP cleavage-activating protein (SCAP). When cholesterol levels fall, the complex moves into the Golgi, where SREBP undergoes successive proteolytic cleavages, releasing the domain for transcription of genes responsible for cholesterol biosynthesis. Conversely, in the presence of cholesterol or its derivatives, insulin-induced gene (Insig) binds to the SCAP-SREBP complex to inhibit SREBP transcriptional activity.

The LXR-RXR transcriptional axis upregulates genes responsible for cholesterol efflux [15]. LXRs are nuclear receptors that form obligate heterodimers with RXRs, which remain bound to DNA elements of target genes regardless of sterol levels. Both isoforms of LXR ( $\alpha$ and $\beta$ ) are expressed in the brain. To modulate their transcriptional activity in the absence of cholesterol derivatives, a corepressor complex interacts with the heterodimer to prevent transcription. However, in the presence of oxysterol ligands, LXR undergoes a conformational change, dissociates from the corepressor complex, and recruits a coactivator complex to promote target gene expression [15].

The 'canonical' roles of SREBP and LXR in cholesterol synthesis and efflux in the brain are well established in the literature, but these factors are also involved in the cholesterol-intensive processes of cell proliferation, neuron migration, and myelination.

\section{SREBP-mediated transcriptional control for brain development and function}

SREBP-mediated transcription is required for regulating normal levels of cholesterol synthesis and is critical for the survival of embryonic cells $[145,146]$. As one of the main cholesterol synthesizers in the brain, astrocytes require SREBP to upregulate cholesterol biosynthetic enzymes, and its activity is modulated by SCAP $[17,147,148]$. The cholesterol generated in astrocytes can then be taken up by neurons for neuronal growth and synaptic maintenance. Mice with SREBP-2 specific knockouts in CNS astrocytes 
survive after birth, but display microcephaly, impaired brain development, and behavioral and motor defects [34]. Similarly, neurological deficits and early mortality are seen in mice with a loss of astrocytic SCAP $[26,149]$. In neuron-astrocyte co-cultures, SREBP-2-regulated transcription in astrocytes is critical for neurite outgrowth [34]. Curiously, mice with a loss of astrocytic SREBP2 display metabolic defects including adiposity reduction and a shift in their metabolism towards carbohydrate oxidation, driven by increased glucose oxidation by the brain [34]. A complex crosstalk between carbohydrate and cholesterol pathways may be present in the brain, and extricating the underlying mechanisms involved is important for understanding the potential relationships between brain health, neurodegenerative conditions, and metabolic disorders.

To date, the importance of SREBP transcription factors in other brain cell types has not been examined closely. SREBP is likely to be critical for oligodendrocytes and developing neurons, which are other major sites for cholesterol synthesis in the brain. Mice with a whole-body disruption of one Insig isoform were viable and showed close to normal lipid metabolism, suggesting potential compensation by the other Insig isoform or other mechanisms [150-152]. Nevertheless, an animal model with CNS-specific perturbations to both Insig-1 and Insig-2 isoforms may provide further insights into the regulation of the SREBP pathway in the brain.

\section{LXR-mediated transcriptional control for brain development and function}

In the brain, LXR activation directly upregulates the transcription of cholesterol transporters, and indirectly downregulates cellular cholesterol uptake. LXR controls the transcription of ApoE and ABC transporters including ABCA1 and ABCG1 [153], which lipidated apolipoproteins for intercellular cholesterol distribution [15]. Meanwhile, LXR also transcriptionally upregulates the gene, inducible degrader of the LDLR (Idol) [154]. Idol is an E3 ubiquitin ligase that specifically targets LDLR for proteasomal degradation and thus decreases cholesterol uptake into the cell. Disruption of both $\operatorname{LXR} \alpha$ and $\beta$ isoforms in mice leads to pathological changes in the brain, including lipid accumulation and neurodegeneration, with significant downregulations in the mRNA levels of direct LXR targets, including $A B C A 1$ and $A B C G 1$ gene expression, as well as indirect LXR targets, including $L D L R, S R E B P-1 C$, and SREBP-2 genes and cholesterol synthesis genes [155].

The LXR pathway itself is regulated by an endoplasmic reticulum-bound transcription factor, nuclear factor erythroid 2 related factor 1 (NRF1). Under low cholesterol conditions, NRF1 translocates into the nucleus and represses the LXR pathway, preventing cholesterol removal. However, in situations of cholesterol excess, cholesterol-binding retains the transcription factor in the endoplasmic reticulum, resulting in a de-repression of LXR activity and activation of cholesterol export [156]. Thus, NRF1 is a master regulator of the LXR pathway, and, indeed in the mouse liver, it exerts a protective effect by preventing cholesterol accumulation and suppressing inflammation. Although, NRF1-mediated control of cholesterol levels has not been well investigated in the brain, disrupting its activity in mouse neurons leads to neurodegeneration [157], suggesting the importance of NRF1 in this organ.

During brain development, LXR signaling influences neuronal migration, where cells arrange themselves in appropriate spatio-temporal patterns to optimize neuronal circuit function [158]. When LXR $\beta$ is knocked out in mice, neuronal migration is unsuccessful and disorganized [159]. This could occur via LXR-mediated modulation of the Reelin signaling pathway, which is responsible for controlling neuronal migration and the formation of cellular layers [160]. The LXR target, Idol, has been shown to regulate expression of the Reelin and lipoprotein receptors, very-LDLR (VLDLR), and ApoE receptor 2, in vitro [18, 161]. Correspondingly, in vivo pharmacological activation of the LXR pathway in mice increases Idol expression and decreases VLDLR levels [18]. Evidently, neuron migration in developing brains and cholesterol transport is coordinated by the same cellular machinery. Consequently, the crosstalk between LXR-mediated cholesterol transport and Reelin signaling is a potential avenue for research.

Myelin production and repair are also regulated by LXR signaling. Thinner myelin sheaths, and altered motor coordination and spatial learning linked to cerebellar deficits, are seen in LXR $\alpha / \beta$-double knockout mice [162]. Primary murine oligodendrocytes in culture require LXR for maturation [162], and during 
differentiation, LXR $\beta$ expression is increased at both neonatal and adult life stages. Treating differentiating primary murine oligodendrocytes with a synthetic LXR ligand-induced cholesterol efflux [19]. Oligodendrocyte differentiation is required for myelin repair and the LXR signaling pathways could be a potential therapeutic target for treating demyelination in multiple sclerosis [49].

\section{Cholesterol removal pathways from the brain}

Despite highly efficient reutilization of cholesterol in the brain, circumstances may arise in which cholesterol levels exceed cellular requirements, necessitating clearance mechanisms in order to maintain homeostasis. Three metabolic pathways are possible, including esterification followed by intracellular storage, efflux of apolipoprotein-cholesterol complexes from the brain via CSF or the blood-brain barrier, and conversion into $24 S$-HC.

\section{Esterification}

Excess cholesterol can be esterified and stored within intracellular organelles known as lipid droplets. Within the brain, cholesteryl esters only constitute $\sim 1 \%$ of total cholesterol content. Esterification occurs through the action of acyl-CoA: cholesterol acyltransferase 1 (ACAT1), which is localized in the endoplasmic reticulum [25]. ACAT1 expression and activity have been detected in neurons, but not in glial cells [163]. However, cholesterol esterification by ACAT1 may be induced in astrocytes under conditions of cholesterol loading or absence of ApoE [130]. Not only do lipid droplets protect cells from toxic accumulation of excess lipids, but they also serve as reservoirs of cholesteryl esters and triglycerides, which can be hydrolyzed into free cholesterol and fatty acids respectively, to fulfill cellular needs for cell signaling, membrane formation, and energy production $[164,165]$.

\section{Direct export from brain}

Cholesterol may be eliminated directly from the brain complexed with apolipoproteins. Cholesterol bound to ApoA-I or ApoE is released by glial cells into the CSF, and subsequently cleared from the brain via CSF bulk flow [166]. However, this only constitutes a minor elimination pathway as it is estimated to remove $2 \mathrm{mg}$ of cholesterol each day [166].

Although it is widely recognized that cholesterol is unable to pass through the blood-brain barrier owing to the presence of tight junctions [167], interestingly, one study has reported direct transport of free cholesterol across the blood-brain barrier via ABCA1 in mice [168]. It also remains possible that physiological and morphological changes to the blood-brain barrier as a result of age or neurodegenerative disease may compromise its permeability, rendering a greater likelihood of leakage of substances, including cholesterol, into and out of the brain [169]. Indeed, increased leakage of oxysterols out of the brain at the blood-brain barrier has been reported in pericyte-deficient mice [170].

\section{Conversion into $24 S$-HC}

The third and most quantitatively significant route of elimination of cholesterol from the brain involves conversion into the oxysterol, 24S-HC. Excess cholesterol undergoes $24 S$-hydroxylation by the CYP enzyme, CYP46A1 (also known as cholesterol 24-hydroxylase), producing a less hydrophobic molecule that traverses lipophilic membranes much more readily than cholesterol $[25,171,172]$. Deletion of CYP46A1 in mice reduces cholesterol efflux from the brain by $64 \%$, highlighting the importance of this elimination pathway [172]. CYP46A1 is localized to neurons of the brain. Immunohistochemical analyses have identified its expression in the endoplasmic reticulum of cortical pyramidal cells, Purkinje cells of the cerebellum, and hippocampal and thalamic neurons $[173,174]$, thus implicating neurons as the primary site for the initiation of cholesterol turnover in the brain. Despite this, some studies have demonstrated that CYP46A1 expression may occur in microglia and astrocytes in circumstances of brain injury or disease, however, its functionality at these sites has not yet been confirmed [175-178]. Although it is generally accepted that $24 S$-HC can passively diffuse across the neuronal membrane, Matsuda et al [94] demonstrated that 24S-HC may be actively exported from SH-SY5Y neuronal cells by ABCA1 in the presence of HDL. 
Approximately $1 \%$ of $24 S$-HC flux from the brain occurs via the CSF, while the remaining $99 \%$ occurs via diffusion through the blood-brain barrier [179]. Active transportation by organic anion transporter proteins can also facilitate the removal of $24 S$-HC at the blood-brain barrier [180]. $24 S$-HC is released into circulation at a rate of 6-7 mg/day and delivered to the liver via LDL and HDL for biliary excretion [77, 167, 181]. In healthy individuals, the magnitude of brain flux closely reflects that of hepatic uptake, indicating that $24 S$ - $\mathrm{HC}$ production is exclusive to the brain [181]. However, circulating levels of $24 S$-HC can be affected by age and the brain-to-liver size ratio [182].

\section{The essential role of oxysterols in the brain}

In addition to serving as the major form by which excess cholesterol is removed from the brain, oxysterols can also influence cholesterol homeostasis at the transcriptional and post-translational levels. For instance, 24S-HC and 27-HC are ligands for LXR in neurons and initiate transcription of cholesterol transport genes [183-185]. Other oxysterols, such as 24,25-EC, can activate the Hedgehog pathway, which is critical for embryogenesis [5, 186, 187].

Recently, oxysterols have been implicated in many neurodegenerative diseases including multiple sclerosis and Alzheimer's disease [49], where increased oxysterol levels are associated with adverse diagnostic and clinical outcomes [188], suggesting the clinical potential for oxysterols as biomarkers and therapeutic targets.

\section{$24 S$-HC}

24S-HC is one of the most abundant oxysterols in the brain [15]. The CYP46A1 enzyme serves a dedicated function in producing the brain-specific oxysterol to remove excess cholesterol from the brain [186]. 24S-HC can also facilitate cholesterol homeostasis via transcriptional regulation [45]. In situations of cholesterol excess, $24 S$-HC inhibits SREBP-2 to suppress cholesterol biosynthesis in glial cells [189, 190]. 24S-HC also serves as a ligand for LXR, mediating the expression of target genes encoding cholesterol transporters, ApoE, $\mathrm{ABCA1}$, and ABCG1, thus promoting the distribution of cholesterol from astrocytes to neurons [191].

Other functions of $24 S$-HC unrelated to cholesterol metabolism include modulation of $\mathrm{A} \beta$ production, prevention of tau hyperphosphorylation, and induction of $N$-methyl- $D$-aspartate receptor-mediated excitotoxicity. Excess accumulation of $24 S$-HC may promote oxidative stress and cytotoxicity [191, 192]. 24S-HC may also be involved in the pathogenesis of neurodegenerative disorders and could be a suitable biomarker for such conditions, as its level reflects the number of metabolically active neurons in the brain $[193,194]$.

\section{7-HC}

While $24 S$ - $\mathrm{HC}$ is the predominant oxysterol generated in the brain, the analogous oxysterol generated in the periphery is 27-HC. Excess cholesterol is converted to 27-HC by the CYP 27A1 enzyme in the first step of the alternative bile acid synthesis pathway, which can then diffuse across the blood-brain barrier into the brain at a rate of $5 \mathrm{mg} /$ day $[77,195,196]$. Decreased levels of oxysterol are observed in Alzheimer's, Parkinson's, and Huntington's diseases [5]. Correspondingly, treatment of primary human neurons with 27-HC has been shown to downregulate $A \beta$ production, potentially in an LXR-mediated manner [183], suggesting that the oxysterol is a possible therapeutic target for Alzheimer's disease. 27-HC may promote LXR activation, as the peripheral injection of the oxysterol into rats has been shown to upregulate $L X R \alpha$ and $A B C A 1$ in the brain, and downregulate genes for cholesterol synthesis, and uptake [197]. However, high doses of 27-HC impair spatial memory performance [197] and further studies are required to understand how 27-HC is involved in brain function.

\section{4,25-EC}

24,25-EC is produced differently from other oxysterols; it is not derived from cholesterol but generated from sterol intermediates. Partial inhibition of the LSS enzyme channels sterol intermediates into the epoxycholesterol Shunt pathway, where epoxylanosterol is metabolized into 24,25-EC (Figure 1) [198]. In 
addition, desmosterol can be converted into epoxycholesterol by the action of CYP46A1 [199]. 24,25-EC is produced in human brains [200], and in rat neonate brains it is more abundant than 24S-HC [201].

24,25-EC is involved in the development and maintenance of brain function. Increasing flux in the Shunt pathway via LSS inhibition enhances oligodendrocyte formation and remyelination [202]. Overexpression of human CYP46A1 in mice increases levels of 24S-HC and 24,25-EC, and this is associated with enhanced midbrain dopamine neurogenesis [203], a process important for controlling voluntary movement, reward processing, and working memory [204]. It is uncertain whether CYP46A1 activity or the epoxycholesterol Shunt pathway is more important for 24,25-EC production in the brain, but an interplay between the two mechanisms is likely [186].

\section{Conclusions}

Our understanding of cholesterol synthesis and disposal in the brain has progressed significantly over the past few decades, however many questions remain unanswered. Which cell type synthesizes the most cholesterol during development and maturation? Do cells in the brain exhibit preference for the usage of the Kandutsch-Russell or Bloch pathways, and does this change over the course of an individual's life? Is there an interplay between the roles of ApoE and clusterin as cholesterol carriers with their non-lipid trafficking duties, and how do they confer pathological risk in Alzheimer's disease? To what degree do ABC lipid transporters share substrates and functionalities between the periphery and CNS? What functions do oxysterols serve in the human brain and could they be used as biomarkers and therapeutic targets for neurodegenerative disorders?

The precise mechanisms for cholesterol regulation are still yet to be elucidated for the brain, due to the predominance of studies focusing on peripheral tissues [205]. Nonetheless, transcriptional and post-translational machinery necessary for homeostatic control of cholesterol expression are present in the brain [17-19], and it is likely that the regulation of brain cholesterol is similar to that which occurs in peripheral tissues. While we have a general understanding of how cholesterol is regulated within the main cholesterol synthesizing cells, astrocytes, and oligodendrocytes, a particular focus on other cell types such as neurons, is warranted. Further studies on the roles of $\mathrm{ABC}$ transporters in mediating cholesterol distribution within the brain will also facilitate our understanding of how cholesterol homeostasis is maintained within the brain, and how disruptions to their activity may elicit pathogenic consequences.

Cholesterol serves crucial structural, functional, and supportive roles in the brain. Cholesterol deficiency and excess cholesterol in the brain can contribute to the pathogenesis of diseases alike [20,22, 49, 206, 207]. Thus, elucidating the nuances of cholesterol regulation, from its synthesis, to distribution, and to disposal, from the brain, provides a critical foundation upon which developments in the understanding of the pathophysiology of neurodegenerative and metabolic disorders can be made.

\section{Abbreviations}

24,25-EC: 24(S),25-epoxycholesterol

24S-HC: 24(S)-hydroxycholesterol

27-HC: 27-hydroxycholesterol

ABC: ATP-binding cassette

ABCA1: ATP-binding cassette transporter subfamily A member 1

ABCB: ATP-binding cassette transporter subfamily $B$

ABCC: ATP-binding cassette transporter subfamily $C$

ABCG1: ATP-binding cassette transporter subfamily G member 1

ACAT1: acyl-coenzyme A: cholesterol acyltransferase 1

ApoE: apolipoprotein E

$\mathrm{A} \beta$ : amyloid-beta 
CNS: central nervous system

CoA: coenzyme A

CSF: cerebrospinal fluid

CYP46A1: cytochrome P450 46A1

DHCR14: 14-dehydrocholesterol reductase

DOS: dioxidosqualene

HDL: high-density lipoprotein

HMG: 3-hydroxy-3-methylglutaryl

HMGCR: 3-hydroxy-3-methylglutaryl-coenzyme A reductase

Idol: inducible degrader of low-density lipoprotein receptor

Insig: insulin-induced gene

K-R: Kandutsch-Russell pathway

LDL: low-density lipoprotein

LDLR: low-density lipoprotein receptor

LDM: lanosterol $14 \alpha$-demethylase

LRP1: low-density lipoprotein receptor-related protein 1

LSS: lanosterol synthase

LXR: liver X receptor

MOS: monooxidosqualene

NRF1: nuclear factor erythroid 2 related factor 1

NSDHL: NAD(P) dependent steroid dehydrogenase-like

PC: phosphatidylcholine

PG: phosphatidylglycerol

RXR: retinoid $X$ receptor

SCAP: sterol regulatory element-binding protein cleavage-activating protein

SM: squalene monooxygenase

SQS: squalene synthase

SREBP: sterol regulatory element-binding protein

TREM2: triggering receptor expressed on myeloid cells 2

\section{Declarations}

Acknowledgements

The authors thank members of the Brown laboratory for their intellectual assistance to this review.

\section{Author contributions}

AJB and ICG: funding acquisition and conceptualization. AJB, ICG, ABC, LQ: writing-original draft and editing. LQ and ABC: visualization and preparation of figures and tables. All authors approved the final version.

\section{Conflicts of interest}

The authors declare that they have no conflicts of interest.

Ethical approval

Not applicable. 


\section{Consent to participate}

Not applicable.

Consent to publication

Not applicable.

Availability of data and materials

Not applicable.

\section{Funding}

This work was supported by the Australian Research Council Discovery Project Grant [DP170101178]. Amanda B. Chai and Lydia Qian are supported by an Australian Research Training Program scholarship. The funders had no role in study design, data collection and analysis, decision to publish, or preparation of the manuscript.

\section{Copyright}

(C) The Author(s) 2022.

\section{References}

1. Björkhem I, Meaney S. Brain cholesterol: long secret life behind a barrier. Arterioscler Thromb Vasc Biol. 2004;24:806-15.

2. Allen JA, Halverson-Tamboli RA, Rasenick MM. Lipid raft microdomains and neurotransmitter signalling. Nat Rev Neurosci. 2007;8:128-40.

3. Gamba P, Staurenghi E, Testa G, Giannelli S, Sottero B, Leonarduzzi G. A crosstalk between brain cholesterol oxidation and glucose metabolism in Alzheimer's disease. Front Neurosci. 2019;13:556.

4. Krause MR, Regen SL. The structural role of cholesterol in cell membranes: from condensed bilayers to lipid rafts. Acc Chem Res. 2014;47:3512-21.

5. Luu W, Sharpe LJ, Capell-Hattam I, Gelissen IC, Brown AJ. Oxysterols: old tale, new twists. Annu Rev Pharmacol Toxicol. 2016;56:447-67.

6. Björkhem I. Crossing the barrier: oxysterols as cholesterol transporters and metabolic modulators in the brain. J Intern Med. 2006;260:493-508.

7. Yang J, Wang L, Jia R. Role of de novo cholesterol synthesis enzymes in cancer. J Cancer. 2020;11:1761-7.

8. Liu M, Kuhel DG, Shen L, Hui DY, Woods SC. Apolipoprotein E does not cross the blood-cerebrospinal fluid barrier, as revealed by an improved technique for sampling CSF from mice. Am J Physiol Regul Integr Comp Physiol. 2012;303:R903-8.

9. Quan G, Xie C, Dietschy JM, Turley SD. Ontogenesis and regulation of cholesterol metabolism in the central nervous system of the mouse. Brain Res Dev Brain Res. 2003;146:87-98.

10. Andersson M, Elmberger PG, Edlund C, Kristensson K, Dallner G. Rates of cholesterol, ubiquinone, dolichol and dolichyl-P biosynthesis in rat brain slices. FEBS Lett. 1990;269:15-8.

11. Zhang J, Liu Q. Cholesterol metabolism and homeostasis in the brain. Protein Cell. 2015;6:254-64.

12. Valenza M, Marullo M, Di Paolo E, Cesana E, Zuccato C, Biella G, et al. Disruption of astrocyte-neuron cholesterol cross talk affects neuronal function in Huntington's disease. Cell Death Differ. 2015;22:690-702.

13. Gill S, Stevenson J, Kristiana I, Brown AJ. Cholesterol-dependent degradation of squalene monooxygenase, a control point in cholesterol synthesis beyond HMG-CoA reductase. Cell Metab. 2011;13:260-73.

14. Brown MS, Radhakrishnan A, Goldstein JL. Retrospective on cholesterol homeostasis: the central role of scap. Annu Rev Biochem. 2018;87:783-807. 
15. Courtney R, Landreth GE. LXR regulation of brain cholesterol: from development to disease. Trends Endocrinol Metab. 2016;27:404-14.

16. Sharpe LJ, Coates HW, Brown AJ. Post-translational control of the long and winding road to cholesterol. J Biol Chem. 2020;295:17549-59.

17. Engelking LJ, Cantoria MJ, Xu Y, Liang G. Developmental and extrahepatic physiological functions of SREBP pathway genes in mice. Semin Cell Dev Biol. 2018;81:98-109.

18. Hong C, Duit S, Jalonen P, Out R, Scheer L, Sorrentino V, et al. The E3 ubiquitin ligase IDOL induces the degradation of the low density lipoprotein receptor family members VLDLR and ApoER2. J Biol Chem. 2010;285:19720-6.

19. Nelissen K, Mulder M, Smets I, Timmermans S, Smeets K, Ameloot M, et al. Liver X receptors regulate cholesterol homeostasis in oligodendrocytes. J Neurosci Res. 2012;90:60-71.

20. Feringa FM, van der Kant R. Cholesterol and Alzheimer's disease; from risk genes to pathological effects. Front Aging Neurosci. 2021;13:690372.

21. Nowaczyk MJM, Irons MB. Smith-Lemli-Opitz syndrome: phenotype, natural history, and epidemiology. Am J Med Genet C Semin Med Genet. 2012;160C:250-62.

22. Pineda-Torra I, Siddique S, Waddington KE, Farrell R, Jury EC. Disrupted lipid metabolism in multiple sclerosis: a role for liver X receptors? Front Endocrinol (Lausanne). 2021;12:639757.

23. Saito M, Benson EP, Saito M, Rosenberg A. Metabolism of cholesterol and triacylglycerol in cultured chick neuronal cells, glial cells, and fibroblasts: accumulation of esterified cholesterol in serum-free culture. J Neurosci Res. 1987;18:319-25.

24. Nieweg K, Schaller H, Pfrieger FW. Marked differences in cholesterol synthesis between neurons and glial cells from postnatal rats. J Neurochem. 2009;109:125-34.

25. Pfrieger FW, Ungerer N. Cholesterol metabolism in neurons and astrocytes. Prog Lipid Res. 2011;50:357-71.

26. van Deijk AF, Camargo N, Timmerman J, Heistek T, Brouwers JF, Mogavero F, et al. Astrocyte lipid metabolism is critical for synapse development and function in vivo. Glia. 2017;65:670-82.

27. Jansen M, Wang W, Greco D, Bellenchi GC, di Porzio U, Brown AJ, et al. What dictates the accumulation of desmosterol in the developing brain? FASEB J. 2013;27:865-70.

28. Genaro-Mattos TC, Anderson A, Allen LB, Korade Z, Mirnics K. Cholesterol biosynthesis and uptake in developing neurons. ACS Chem Neurosci. 2019;10:3671-81.

29. Tracey TJ, Steyn FJ, Wolvetang EJ, Ngo ST. Neuronal lipid metabolism: multiple pathways driving functional outcomes in health and disease. Front Mol Neurosci. 2018;11:10.

30. Saito K, Dubreuil V, Arai Y, Wilsch-Bräuninger M, Schwudke D, Saher G, et al. Ablation of cholesterol biosynthesis in neural stem cells increases their VEGF expression and angiogenesis but causes neuron apoptosis. Proc Natl Acad Sci U S A. 2009;106:8350-5.

31. Fünfschilling U, Saher G, Xiao L, Möbius W, Nave KA. Survival of adult neurons lacking cholesterol synthesis in vivo. BMC Neurosci. 2007;8:1.

32. Lee JA, Hall B, Allsop J, Alqarni R, Allen SP. Lipid metabolism in astrocytic structure and function. Semin Cell Dev Biol. 2021;112:123-36.

33. Barber CN, Raben DM. Lipid metabolism crosstalk in the brain: glia and neurons. Front Cell Neurosci. 2019;13:212.

34. Ferris HA, Perry RJ, Moreira GV, Shulman GI, Horton JD, Kahn CR. Loss of astrocyte cholesterol synthesis disrupts neuronal function and alters whole-body metabolism. Proc Natl Acad Sci U S A. 2017;114:1189-94.

35. Muse ED, Jurevics H, Toews AD, Matsushima GK, Morell P. Parameters related to lipid metabolism as markers of myelination in mouse brain. J Neurochem. 2001;76:77-86. 
36. Saher G, Stumpf SK. Cholesterol in myelin biogenesis and hypomyelinating disorders. Biochim Biophys Acta. 2015;1851:1083-94.

37. Williamson JM, Lyons DA. Myelin dynamics throughout life: an ever-changing landscape? Front Cell Neurosci. 2018;12:424.

38. Saher G, Brügger B, Lappe-Siefke C, Möbius W, Tozawa R, Wehr MC, et al. High cholesterol level is essential for myelin membrane growth. Nat Neurosci. 2005;8:468-75.

39. Werkman IL, Kövilein J, de Jonge JC, Baron W. Impairing committed cholesterol biosynthesis in white matter astrocytes, but not grey matter astrocytes, enhances in vitro myelination. J Neurochem. 2021;156:624-41.

40. Loving BA, Bruce KD. Lipid and lipoprotein metabolism in microglia. Front Physiol. 2020;11:393.

41. Paolicelli RC, Bolasco G, Pagani F, Maggi L, Scianni M, Panzanelli P, et al. Synaptic pruning by microglia is necessary for normal brain development. Science. 2011;333:1456-8.

42. Berghoff SA, Spieth L, Sun T, Hosang L, Schlaphoff L, Depp C, et al. Microglia facilitate repair of demyelinated lesions via post-squalene sterol synthesis. Nat Neurosci. 2021;24:47-60.

43. Bohlen CJ, Bennett FC, Tucker AF, Collins HY, Mulinyawe SB, Barres BA. Diverse requirements for microglial survival, specification, and function revealed by defined-medium cultures. Neuron. 2017;94:759-73.e8.

44. Valdez CM, Smith MA, Perry G, Phelix CF, Santamaria F. Cholesterol homeostasis markers are localized to mouse hippocampal pyramidal and granule layers. Hippocampus. 2010;20:902-5.

45. Pfrieger FW. Outsourcing in the brain: do neurons depend on cholesterol delivery by astrocytes? Bioessays. 2003;25:72-8.

46. Ohashi K, Osuga J, Tozawa R, Kitamine T, Yagyu H, Sekiya M, et al. Early embryonic lethality caused by targeted disruption of the 3-hydroxy-3-methylglutaryl-CoA reductase gene. J Biol Chem. 2003;278:42936-41.

47. Tozawa R, Ishibashi S, Osuga J, Yagyu H, Oka T, Chen Z, et al. Embryonic lethality and defective neural tube closure in mice lacking squalene synthase. J Biol Chem. 1999;274:30843-8.

48. Mathews ES, Appel B. Cholesterol biosynthesis supports myelin gene expression and axon ensheathment through modulation of P13K/Akt/mTOR signaling. J Neurosci. 2016;36:7628-39.

49. Vejux A, Ghzaiel I, Nury T, Schneider V, Charrière K, Sghaier R, et al. Oxysterols and multiple sclerosis: physiopathology, evolutive biomarkers and therapeutic strategy. J Steroid Biochem Mol Biol. 2021;210:105870.

50. Cantuti-Castelvetri L, Fitzner D, Bosch-Queralt M, Weil MT, Su M, Sen P, et al. Defective cholesterol clearance limits remyelination in the aged central nervous system. Science. 2018;359:684-8.

51. Marschallinger J, Iram T, Zardeneta M, Lee SE, Lehallier B, Haney MS, et al. Lipid-droplet-accumulating microglia represent a dysfunctional and proinflammatory state in the aging brain. Nat Neurosci. 2020;23:194-208.

52. Chen J, Zhang X, Kusumo H, Costa LG, Guizzetti M. Cholesterol efflux is differentially regulated in neurons and astrocytes: implications for brain cholesterol homeostasis. Biochim Biophys Acta. 2013;1831:263-75.

53. Wang H, Eckel RH. What are lipoproteins doing in the brain? Trends Endocrinol Metab. 2014;25:8-14.

54. Camargo N, Goudriaan A, van Deijk AF, Otte WM, Brouwers JF, Lodder H, et al. Oligodendroglial myelination requires astrocyte-derived lipids. PLoS Biol. 2017;15:e1002605.

55. Yeh FL, Wang Y, Tom I, Gonzalez LC, Sheng M. TREM2 binds to apolipoproteins, including APOE and CLU/APOJ, and thereby facilitates uptake of amyloid-beta by microglia. Neuron. 2016;91:328-40.

56. Mauch DH, Nägler K, Schumacher S, Göritz C, Müller EC, Otto A, et al. CNS synaptogenesis promoted by glia-derived cholesterol. Science. 2001;294:1354-7. 
57. Lund EG, Xie C, Kotti T, Turley SD, Dietschy JM, Russell DW. Knockout of the cholesterol 24hydroxylase gene in mice reveals a brain-specific mechanism of cholesterol turnover. J Biol Chem. 2003;278:22980-8.

58. Flowers SA, Rebeck GW. APOE in the normal brain. Neurobiol Dis. 2020;136:104724.

59. Frieden C, Garai K. Structural differences between apoE3 and apoE4 may be useful in developing therapeutic agents for Alzheimer's disease. Proc Natl Acad Sci U S A. 2012;109:8913-8.

60. Frieden C, Wang H, Ho CMW. A mechanism for lipid binding to apoE and the role of intrinsically disordered regions coupled to domain-domain interactions. Proc Natl Acad Sci U S A. 2017;114:6292-7.

61. Garai K, Baban B, Frieden C. Self-association and stability of the ApoE isoforms at low pH: implications for ApoE-lipid interactions. Biochemistry. 2011;50:6356-64.

62. Saito H, Dhanasekaran P, Baldwin F, Weisgraber KH, Lund-Katz S, Phillips MC. Lipid binding-induced conformational change in human apolipoprotein E. Evidence for two lipid-bound states on spherical particles. J Biol Chem. 2001;276:40949-54.

63. Chen J, Li Q, Wang J. Topology of human apolipoprotein E3 uniquely regulates its diverse biological functions. Proc Natl Acad Sci U S A. 2011;108:14813-8.

64. Dong HK, Gim JA, Yeo SH, Kim HS. Integrated late onset Alzheimer's disease (LOAD) susceptibility genes: cholesterol metabolism and trafficking perspectives. Gene. 2017;597:10-6.

65. Calero M, Tokuda T, Rostagno A, Kumar A, Zlokovic B, Frangione B, et al. Functional and structural properties of lipid-associated apolipoprotein J (clusterin). Biochem J. 1999;344:375-83.

66. Rodríguez-Rivera C, Garcia MM, Molina-Álvarez M, González-Martín C, Goicoechea C. Clusterin: always protecting. Synthesis, function and potential issues. Biomed Pharmacother. 2021;134:111174.

67. Artemaki PI, Sklirou AD, Kontos CK, Liosi AA, Gianniou DD, Papadopoulos IN, et al. High clusterin (CLU) mRNA expression levels in tumors of colorectal cancer patients predict a poor prognostic outcome. Clin Biochem. 2020;75:62-9.

68. Ding X, Zhang W, Li S, Yang H. The role of cholesterol metabolism in cancer. Am J Cancer Res. 2019;9:219-27.

69. Debure L, Vayssiere JL, Rincheval V, Loison F, Le Drean Y, Michel D. Intracellular clusterin causes juxtanuclear aggregate formation and mitochondrial alteration. J Cell Sci. 2003;116:3109-21.

70. Herring SK, Moon HJ, Rawal P, Chhibber A, Zhao L. Brain clusterin protein isoforms and mitochondrial localization. Elife. 2019;8:e48255.

71. Riwanto M, Rohrer L, Roschitzki B, Besler C, Mocharla P, Mueller M, et al. Altered activation of endothelial anti- and proapoptotic pathways by high-density lipoprotein from patients with coronary artery disease: role of high-density lipoprotein-proteome remodeling. Circulation. 2013;127:891-904.

72. Gong JS, Kobayashi M, Hayashi H, Zou K, Sawamura N, Fujita SC, et al. Apolipoprotein E (ApoE) isoform-dependent lipid release from astrocytes prepared from human ApoE3 and ApoE4 knock-in mice. J Biol Chem. 2002;277:29919-26.

73. Vance JE, Hayashi H. Formation and function of apolipoprotein E-containing lipoproteins in the nervous system. Biochim Biophys Acta. 2010;1801:806-18.

74. de Silva HV, Harmony JA, Stuart WD, Gil CM, Robbins J. Apolipoprotein J: structure and tissue distribution. Biochemistry. 1990;29:5380-9.

75. Gil SY, Youn BS, Byun K, Huang H, Namkoong C, Jang PG, et al. Clusterin and LRP2 are critical components of the hypothalamic feeding regulatory pathway. Nat Commun. 2013;4:1862.

76. Elliott DA, Weickert CS, Garner B. Apolipoproteins in the brain: implications for neurological and psychiatric disorders. Clin Lipidol. 2010;51:555-73.

77. Orth M, Bellosta S. Cholesterol: its regulation and role in central nervous system disorders. Cholesterol. 2012;2012:292598. 
78. Strittmatter WJ, Weisgraber KH, Huang DY, Dong LM, Salvesen GS, Pericak-Vance M, et al. Binding of human apolipoprotein $\mathrm{E}$ to synthetic amyloid beta peptide: isoform-specific effects and implications for late-onset Alzheimer disease. Proc Natl Acad Sci U S A. 1993;90:8098-102.

79. Yamazaki Y, Zhao N, Caulfield TR, Liu CC, Bu G. Apolipoprotein E and Alzheimer disease: pathobiology and targeting strategies. Nat Rev Neurol. 2019;15:501-18.

80. Cutler RG, Kelly J, Storie K, Pedersen WA, Tammara A, Hatanpaa K, et al. Involvement of oxidative stress-induced abnormalities in ceramide and cholesterol metabolism in brain aging and Alzheimer's disease. Proc Natl Acad Sci U S A. 2004;101:2070-5.

81. Xiong H, Callaghan D, Jones A, Walker DG, Lue LF, Beach TG, et al. Cholesterol retention in Alzheimer's brain is responsible for high beta- and gamma-secretase activities and Abeta production. Neurobiol Dis. 2008;29:422-37.

82. Chai AB, Lam HHJ, Kockx M, Gelissen IC. Apolipoprotein E isoform-dependent effects on the processing of Alzheimer's amyloid- $\beta$. Biochim Biophys Acta Mol Cell Biol Lipids. 2021;1866:158980.

83. Wyatt AR, Yerbury JJ, Berghofer P, Greguric I, Katsifis A, Dobson CM, et al. Clusterin facilitates in vivo clearance of extracellular misfolded proteins. Cell Mol Life Sci. 2011;68:3919-31.

84. Bell RD, Sagare AP, Friedman AE, Bedi GS, Holtzman DM, Deane R, et al. Transport pathways for clearance of human Alzheimer's amyloid beta-peptide and apolipoproteins $\mathrm{E}$ and $\mathrm{J}$ in the mouse central nervous system. J Cereb Blood Flow Metab. 2007;27:909-18.

85. Su H, Rustam YH, Masters CL, Makalic E, McLean CA, Hill AF, et al. Characterization of brain-derived extracellular vesicle lipids in Alzheimer's disease. J Extracell Vesicles. 2021;10:e12089.

86. Wilkens S. Structure and mechanism of ABC transporters. F1000Prime Rep. 2015;7:14.

87. Kim WS, Guillemin GJ, Glaros EN, Lim CK, Garner B. Quantitation of ATP-binding cassette subfamily-A transporter gene expression in primary human brain cells. Neuroreport. 2006;17:891-6.

88. Kim WS, Rahmanto AS, Kamili A, Rye KA, Guillemin GJ, Gelissen IC, et al. Role of ABCG1 and ABCA1 in regulation of neuronal cholesterol efflux to apolipoprotein $\mathrm{E}$ discs and suppression of amyloid-beta peptide generation. J Biol Chem. 2007;282:2851-61.

89. Kim WS, Weickert CS, Garner B. Role of ATP-binding cassette transporters in brain lipid transport and neurological disease. J Neurochem. 2008;104:1145-66.

90. Fujiyoshi M, Ohtsuki S, Hori S, Tachikawa M, Terasaki T. 24S-hydroxycholesterol induces cholesterol release from choroid plexus epithelial cells in an apical- and apoE isoform-dependent manner concomitantly with the induction of ABCA1 and ABCG1 expression. J Neurochem. 2007;100:968-78.

91. Hartz AMS, Bauer B. ABC transporters in the CNS—an inventory. Curr Pharm Biotechnol. 2011;12:656-73.

92. Lin T, Islam 0 , Heese $\mathrm{K}$. ABC transporters, neural stem cells and neurogenesis-a different perspective. Cell Res. 2006;16:857-71.

93. Vaughan AM, Oram JF. ABCA1 and ABCG1 or ABCG4 act sequentially to remove cellular cholesterol and generate cholesterol-rich HDL. J Lipid Res. 2006;47:2433-43.

94. Matsuda A, Nagao K, Matsuo M, Kioka N, Ueda K. 24(S)-hydroxycholesterol is actively eliminated from neuronal cells by ABCA1. J Neurochem. 2013;126:93-101.

95. Oram JF. HDL apolipoproteins and ABCA1: partners in the removal of excess cellular cholesterol. Arterioscler Thromb Vasc Biol. 2003;23:720-7.

96. Warren MS, Zerangue N, Woodford K, Roberts LM, Tate EH, Feng B, et al. Comparative gene expression profiles of $A B C$ transporters in brain microvessel endothelial cells and brain in five species including human. Pharmacol Res. 2009;59:404-13.

97. Sakai H, Tanaka Y, Tanaka M, Ban N, Yamada K, Matsumura Y, et al. ABCA2 deficiency results in abnormal sphingolipid metabolism in mouse brain. J Biol Chem. 2007;282:19692-9. 
98. Calpe-Berdiel L, Zhao Y, de Graauw M, Ye D, van Santbrink PJ, Mommaas AM, et al. Macrophage ABCA2 deletion modulates intracellular cholesterol deposition, affects macrophage apoptosis, and decreases early atherosclerosis in LDL receptor knockout mice. Atherosclerosis. 2012;223:332-41.

99. Davis W Jr. The ATP-binding cassette transporter-2 (ABCA2) regulates cholesterol homeostasis and low-density lipoprotein receptor metabolism in N2a neuroblastoma cells. Biochim Biophys Acta. 2011;1811:1152-64.

100. Ban N, Matsumura Y, Sakai H, Takanezawa Y, Sasaki M, Arai H, et al. ABCA3 as a lipid transporter in pulmonary surfactant biogenesis. J Biol Chem. 2007;282:9628-34.

101. Fitzgerald ML, Xavier R, Haley KJ, Welti R, Goss JL, Brown CE, et al. ABCA3 inactivation in mice causes respiratory failure, loss of pulmonary surfactant, and depletion of lung phosphatidylglycerol. J Lipid Res. 2007;48:621-32.

102. Cheong N, Madesh M, Gonzales LW, Zhao M, Yu K, Ballard PL, et al. Functional and trafficking defects in ATP binding cassette A3 mutants associated with respiratory distress syndrome. J Biol Chem. 2006;281:9791-800.

103. Ikeda Y, Abe-Dohmae S, Munehira Y, Aoki R, Kawamoto S, Furuya A, et al. Posttranscriptional regulation of human ABCA7 and its function for the apoA-I-dependent lipid release. Biochem Biophys Res Commun. 2003;311:313-8.

104. Wang N, Lan D, Gerbod-Giannone M, Linsel-Nitschke P, Jehle AW, Chen W, et al. ATP-binding cassette transporter A7 (ABCA7) binds apolipoprotein A-I and mediates cellular phospholipid but not cholesterol efflux. J Biol Chem. 2003;278:42906-12.

105. Chan SL, Kim WS, Kwok JB, Hill AF, Cappai R, Rye KA, et al. ATP-binding cassette transporter A7 regulates processing of amyloid precursor protein in vitro. J Neurochem. 2008;106:793-804.

106. Matsumoto N, Kitayama H, Kitada M, Kimura K, Noda M, Ide C. Isolation of a set of genes expressed in the choroid plexus of the mouse using suppression subtractive hybridization. Neuroscience. 2003;117:405-15.

107. Trigueros-Motos L, van Capelleveen JC, Torta F, Castaño D, Zhang LH, Chai EC, et al. ABCA8 regulates cholesterol efflux and high-density lipoprotein cholesterol levels. Arterioscler Thromb Vasc Biol. 2017;37:2147-55.

108. Kooij G, van Horssen J, Bandaru VV, Haughey NJ, de Vries HE. The role of ATP-binding cassette transporters in neuro-inflammation: relevance for bioactive lipids. Front Pharmacol. 2012;3:74.

109. Mahringer A, Fricker G. ABC transporters at the blood-brain barrier. Expert Opin Drug Metab Toxicol. 2016;12:499-508.

110. Neumann J, Rose-Sperling D, Hellmich UA. Diverse relations between ABC transporters and lipids: an overview. Biochim Biophys Acta Biomembr. 2017;1859:605-18.

111. Pohl A, Lage H, Müller P, Pomorski T, Herrmann A. Transport of phosphatidylserine via MDR1 (multidrug resistance 1)P-glycoprotein in a human gastric carcinoma cell line. Biochem J. 2002;365:259-68.

112. van Helvoort A, Smith AJ, Sprong H, Fritzsche I, Schinkel AH, Borst P, et al. MDR1 P-glycoprotein is a lipid translocase of broad specificity, while MDR3 P-glycoprotein specifically translocates phosphatidylcholine. Cell. 1996;87:507-17.

113. Garrigues A, Escargueil AE, Orlowski S. The multidrug transporter, P-glycoprotein, actively mediates cholesterol redistribution in the cell membrane. Proc Natl Acad Sci U S A. 2002;99:10347-52.

114. Le Goff W, Settle M, Greene DJ, Morton RE, Smith JD. Reevaluation of the role of the multidrug-resistant P-glycoprotein in cellular cholesterol homeostasis. J Lipid Res. 2006;47:51-8.

115. Eckford PDW, Sharom FJ. The reconstituted P-glycoprotein multidrug transporter is a flippase for glucosylceramide and other simple glycosphingolipids. Biochem J. 2005;389:517-26.

116. Beck K, Hayashi K, Dang K, Hayashi M, Boyd CD. Analysis of ABCC6 (MRP6) in normal human tissues. Histochem Cell Biol. 2005;123:517-28. 
117. Ibold B, Tiemann J, Faust I, Ceglarek U, Dittrich J, Gorgels TGMF, et al. Genetic deletion of Abcc6 disturbs cholesterol homeostasis in mice. Sci Rep. 2021;11:2137.

118. Fourcade S, Ruiz M, Camps C, Schlüter A, Houten SM, Mooyer PAW, et al. A key role for the peroxisomal ABCD2 transporter in fatty acid homeostasis. Am J Physiol Endocrinol Metab. 2009;296:E211-21.

119. Kawaguchi K, Morita M. ABC transporter subfamily D: distinct differences in behavior between ABCD1-3 and ABCD4 in subcellular localization, function, and human disease. Biomed Res Int. 2016;2016:6786245.

120. Wang N, Yvan-Charvet L, Lütjohann D, Mulder M, Vanmierlo T, Kim TW, et al. ATP-binding cassette transporters G1 and G4 mediate cholesterol and desmosterol efflux to HDL and regulate sterol accumulation in the brain. FASEB J. 2008;22:1073-82.

121. Burgess BL, Parkinson PF, Racke MM, Hirsch-Reinshagen V, Fan J, Wong C, et al. ABCG1 influences the brain cholesterol biosynthetic pathway but does not affect amyloid precursor protein or apolipoprotein E metabolism in vivo. J Lipid Res. 2008;49:1254-67.

122. Kobayashi A, Takanezawa Y, Hirata T, Shimizu Y, Misasa K, Kioka N, et al. Efflux of sphingomyelin, cholesterol, and phosphatidylcholine by ABCG1. J Lipid Res. 2006;47:1791-802.

123. Xu M, Zhou H, Tan KCB, Guo R, Shiu SWM, Wong Y. ABCG1 mediated oxidized LDL-derived oxysterol efflux from macrophages. Biochem Biophys Res Commun. 2009;390:1349-54.

124. Dodacki A, Wortman M, Saubaméa B, Chasseigneaux S, Nicolic S, Prince N, et al. Expression and function of Abcg4 in the mouse blood-brain barrier: role in restricting the brain entry of amyloid- $\beta$ peptide. Sci Rep. 2017;7:13393.

125. Wang N, Lan D, Chen W, Matsuura F, Tall AR. ATP-binding cassette transporters G1 and G4 mediate cellular cholesterol efflux to high-density lipoproteins. Proc Natl Acad Sci U S A. 2004;101:9774-9.

126. Bojanic DD, Tarr PT, Gale GD, Smith DJ, Bok D, Chen B, et al. Differential expression and function of ABCG1 and ABCG4 during development and aging. J Lipid Res. 2010;51:169-81.

127. Yang A, Alrosan AZ, Sharpe LJ, Brown AJ, Callaghan R, Gelissen IC. Regulation of ABCG4 transporter expression by sterols and LXR ligands. Biochim Biophys Acta Gen Subj. 2021;1865:129769.

128. Gelissen IC, Harris M, Rye KA, Quinn C, Brown AJ, Kockx M, et al. ABCA1 and ABCG1 synergize to mediate cholesterol export to apoA-I. Arterioscler Thromb Vasc Biol. 2006;26:534-40.

129. Hirsch-Reinshagen V, Zhou S, Burgess BL, Bernier L, McIsaac SA, Chan JY, et al. Deficiency of ABCA1 impairs apolipoprotein E metabolism in brain. J Biol Chem. 2004;279:41197-207.

130. Karten B, Campenot RB, Vance DE, Vance JE. Expression of ABCG1, but not ABCA1, correlates with cholesterol release by cerebellar astroglia. J Biol Chem. 2006;281:4049-57.

131. Oram JF, Lawn RM. ABCA1: the gatekeeper for eliminating excess tissue cholesterol. J Lipid Res. 2001;42:1173-9.

132. Karasinska JM, Rinninger F, Lütjohann D, Ruddle P, Franciosi S, Kruit JK, et al. Specific loss of brain ABCA1 increases brain cholesterol uptake and influences neuronal structure and function. J Neurosci. 2009;29:3579-89.

133. Wahrle SE, Jiang H, Parsadanian M, Legleiter J, Han X, Fryer JD, et al. ABCA1 is required for normal central nervous system ApoE levels and for lipidation of astrocyte-secreted apoE. J Biol Chem. 2004;279:40987-93.

134. Davis W Jr. The ATP-binding cassette transporter-2 (ABCA2) regulates esterification of plasma membrane cholesterol by modulation of sphingolipid metabolism. Biochim Biophys Acta. 2014; 1841:168-79.

135. De Roeck A, Van Broeckhoven C, Sleegers K. The role of ABCA7 in Alzheimer's disease: evidence from genomics, transcriptomics and methylomics. Acta Neuropathol. 2019;138:201-20. 
136. Lyssenko NN, Praticò D. ABCA7 and the altered lipidostasis hypothesis of Alzheimer's disease. Alzheimers Dement. 2021;17:164-74.

137. Dib S, Pahnke J, Gosselet F. Role of ABCA7 in human health and in Alzheimer's disease. Int J Mol Sci. 2021;22:4603.

138. Steinberg S, Stefansson H, Jonsson T, Johannsdottir H, Ingason A, Helgason H, et al. Loss-of-function variants in ABCA7 confer risk of Alzheimer's disease. Nat Genet. 2015;47:445-7.

139. Kim WS, Hsiao JH, Bhatia S, Glaros EN, Don AS, Tsuruoka S, et al. ABCA8 stimulates sphingomyelin production in oligodendrocytes. Biochem J. 2013;452:401-10.

140. Brampton C, Pomozi V, Chen LH, Apana A, McCurdy S, Zoll J, et al. ABCC6 deficiency promotes dyslipidemia and atherosclerosis. Sci Rep. 2021;11:3881.

141. Kuzaj P, Kuhn J, Dabisch-Ruthe M, Faust I, Götting C, Knabbe C, et al. ABCC6-a new player in cellular cholesterol and lipoprotein metabolism? Lipids Health Dis. 2014;13:118.

142. Cserepes J, Szentpétery Z, Seres L, Ozvegy-Laczka C, Langmann T, Schmitz G, et al. Functional expression and characterization of the human ABCG1 and ABCG4 proteins: indications for heterodimerization. Biochem Biophys Res Commun. 2004;320:860-7.

143. Tarr PT, Edwards PA. ABCG1 and ABCG4 are coexpressed in neurons and astrocytes of the CNS and regulate cholesterol homeostasis through SREBP-2. J Lipid Res. 2008;49:169-82.

144. DeBose-Boyd RA, Ye J. SREBPs in lipid metabolism, insulin signaling, and beyond. Trends Biochem Sci. 2018;43:358-68.

145. Mitchell KJ, Pinson KI, Kelly OG, Brennan J, Zupicich J, Scherz P, et al. Functional analysis of secreted and transmembrane proteins critical to mouse development. Nat Genet. 2001;28:241-9.

146. Shimano H, Shimomura I, Hammer RE, Herz J, Goldstein JL, Brown MS, et al. Elevated levels of SREBP-2 and cholesterol synthesis in livers of mice homozygous for a targeted disruption of the SREBP-1 gene. J Clin Invest. 1997;100:2115-24.

147. Engelking LJ, Evers BM, Richardson JA, Goldstein JL, Brown MS, Liang G. Severe facial clefting in Insig-deficient mouse embryos caused by sterol accumulation and reversed by lovastatin. J Clin Invest. 2006;116:2356-65.

148. Suzuki R, Ferris HA, Chee MJ, Maratos-Flier E, Kahn CR. Reduction of the cholesterol sensor SCAP in the brains of mice causes impaired synaptic transmission and altered cognitive function. PLoS Biol. 2013;11:e1001532.

149. Camargo N, Brouwers JF, Loos M, Gutmann DH, Smit AB, Verheijen MHG. High-fat diet ameliorates neurological deficits caused by defective astrocyte lipid metabolism. FASEB J. 2012;26:4302-15.

150. Engelking LJ, Liang G, Hammer RE, Takaishi K, Kuriyama H, Evers BM, et al. Schoenheimer effect explained-feedback regulation of cholesterol synthesis in mice mediated by Insig proteins. J Clin Invest. 2005;115:2489-98.

151. Hwang S, Nguyen AD, Jo Y, Engelking LJ, Brugarolas J, DeBose-Boyd RA. Hypoxia-inducible factor $1 \alpha$ activates insulin-induced gene 2 (Insig-2) transcription for degradation of 3-hydroxy-3-methylglutaryl (HMG)-CoA reductase in the liver. J Biol Chem. 2017;292:9382-93.

152. Plantier L, Besnard V, Xu Y, Ikegami M, Wert SE, Hunt AN, et al. Activation of sterol-response element-binding proteins (SREBP) in alveolar type II cells enhances lipogenesis causing pulmonary lipotoxicity. J Biol Chem. 2012;287:10099-114.

153. Bilotta MT, Petillo S, Santoni A, Cippitelli M. Liver X receptors: regulators of cholesterol metabolism, inflammation, autoimmunity, and cancer. Front Immunol. 2020;11:584303.

154. Zhang L, Reue K, Fong LG, Young SG, Tontonoz P. Feedback regulation of cholesterol uptake by the LXR-IDOL-LDLR axis. Arterioscler Thromb Vasc Biol. 2012;32:2541-6. 
155. Wang L, Schuster GU, Hultenby K, Zhang Q Andersson S, Gustafsson JA. Liver X receptors in the central nervous system: from lipid homeostasis to neuronal degeneration. Proc Natl Acad Sci U S A. 2002;99:13878-83.

156. Widenmaier SB, Snyder NA, Nguyen TB, Arduini A, Lee GY, Arruda AP, et al. NRF1 is an ER membrane sensor that is central to cholesterol homeostasis. Cell. 2017;171:1094-109.e15.

157. Lee CS, Lee C, Hu T, Nguyen JM, Zhang J, Martin MV, et al. Loss of nuclear factor E2-related factor 1 in the brain leads to dysregulation of proteasome gene expression and neurodegeneration. Proc Natl Acad Sci U S A. 2011;108:8408-13.

158. Rahimi-Balaei M, Bergen H, Kong J, Marzban H. Neuronal migration during development of the cerebellum. Front Cell Neurosci. 2018;12:484.

159. Fan X, Kim HJ, Bouton D, Warner M, Gustafsson JA. Expression of liver X receptor beta is essential for formation of superficial cortical layers and migration of later-born neurons. Proc Natl Acad Sci U S A. 2008;105:13445-50.

160. Do HT, Bruelle C, Tselykh T, Jalonen P, Korhonen L, Lindholm D. Reciprocal regulation of very low density lipoprotein receptors (VLDLRs) in neurons by brain-derived neurotrophic factor (BDNF) and Reelin: involvement of the E3 ligase Mylip/Idol. J Biol Chem. 2013;288:29613-20.

161. Hirota Y, Kubo K, Katayama K, Honda T, Fujino T, Yamamoto TT, et al. Reelin receptors ApoER2 and VLDLR are expressed in distinct spatiotemporal patterns in developing mouse cerebral cortex. J Comp Neurol. 2015;523:463-78.

162. Meffre D, Shackleford G, Hichor M, Gorgievski V, Tzavara ET, Trousson A, et al. Liver X receptors alpha and beta promote myelination and remyelination in the cerebellum. Proc Natl Acad Sci U S A. 2015;112:7587-92.

163. Sakashita N, Miyazaki A, Takeya M, Horiuchi S, Chang CC, Chang TY, et al. Localization of human acyl-coenzyme A: cholesterol acyltransferase-1 (ACAT-1) in macrophages and in various tissues. Am J Pathol. 2000;156:227-36.

164. Chang TY, Chang CCY, Bryleva E, Rogers MA, Murphy SR. Neuronal cholesterol esterification by ACAT1 in Alzheimer's disease. IUBMB Life. 2010;62:261-7.

165. Ralhan I, Chang CL, Lippincott-Schwartz J, Ioannou MS. Lipid droplets in the nervous system. J Cell Biol. 2021;220:e202102136.

166. Pitas RE, Boyles JK, Lee SH, Hui D, Weisgraber KH. Lipoproteins and their receptors in the central nervous system. Characterization of the lipoproteins in cerebrospinal fluid and identification of apolipoprotein B,E(LDL) receptors in the brain. J Biol Chem. 1987;262:14352-60.

167. Mahley RW. Central nervous system lipoproteins: ApoE and regulation of cholesterol metabolism. Arterioscler Thromb Vasc Biol. 2016;36:1305-15.

168. Do TM, Ouellet M, Calon F, Chimini G, Chacun H, Farinotti R, et al. Direct evidence of abca1-mediated efflux of cholesterol at the mouse blood-brain barrier. Mol Cell Biochem. 2011;357:397-404.

169. Pifferi F, Laurent B, Plourde M. Lipid transport and metabolism at the blood-brain interface: implications in health and disease. Front Physiol. 2021;12:645646.

170. Saeed AA, Genové G, Li T, Lütjohann D, Olin M, Mast N, et al. Effects of a disrupted blood-brain barrier on cholesterol homeostasis in the brain. J Biol Chem. 2014;289:23712-22.

171. Björkhem I, Lütjohann D, Breuer O, Sakinis A, Wennmalm A. Importance of a novel oxidative mechanism for elimination of brain cholesterol. Turnover of cholesterol and 24(S)-hydroxycholesterol in rat brain as measured with ${ }^{18} \mathrm{O}_{2}$ techniques in vivo and in vitro. J Biol Chem. 1997;272:30178-84.

172. Xie C, Lund EG, Turley SD, Russell DW, Dietschy JM. Quantitation of two pathways for cholesterol excretion from the brain in normal mice and mice with neurodegeneration. J Lipid Res. 2003;44:1780-9.

173. Lund EG, Guileyardo JM, Russell DW. cDNA cloning of cholesterol 24-hydroxylase, a mediator of cholesterol homeostasis in the brain. Proc Natl Acad Sci U S A. 1999;96:7238-43. 
174. Ramirez DMO, Andersson S, Russell DW. Neuronal expression and subcellular localization of cholesterol 24-hydroxylase in the mouse brain. J Comp Neurol. 2008;507:1676-93.

175. Bogdanovic N, Bretillon L, Lund EG, Diczfalusy U, Lannfelt L, Winblad B, et al. On the turnover of brain cholesterol in patients with Alzheimer's disease. Abnormal induction of the cholesterol-catabolic enzyme CYP46 in glial cells. Neurosci Lett. 2001;314:45-8.

176. Cartagena CM, Ahmed F, Burns MP, Pajoohesh-Ganji A, Pak DT, Faden AI, et al. Cortical injury increases cholesterol 24S hydroxylase (Cyp46) levels in the rat brain. J Neurotrauma. 2008;25:1087-98.

177. Smiljanic K, Lavrnja I, Mladenovic Djordjevic A, Ruzdijic S, Stojiljkovic M, Pekovic S, et al. Brain injury induces cholesterol 24-hydroxylase (Cyp46) expression in glial cells in a time-dependent manner. Histochem Cell Biol. 2010;134:159-69.

178. Tian G, Kong Q, Lai L, Ray-Chaudhury A, Lin CLG. Increased expression of cholesterol 24S-hydroxylase results in disruption of glial glutamate transporter EAAT2 association with lipid rafts: a potential role in Alzheimer's disease. J Neurochem. 2010;113:978-89.

179. Lütjohann D, Breuer O, Ahlborg G, Nennesmo I, Sidén A, Diczfalusy U, et al. Cholesterol homeostasis in human brain: evidence for an age-dependent flux of 24S-hydroxycholesterol from the brain into the circulation. Proc Natl Acad Sci U S A. 1996;93:9799-804.

180. Ohtsuki S, Ito S, Matsuda A, Hori S, Abe T, Terasaki T. Brain-to-blood elimination of 24S-hydroxycholesterol from rat brain is mediated by organic anion transporting polypeptide 2 (oatp2) at the blood-brain barrier. J Neurochem. 2007;103:1430-8.

181. Björkhem I, Lütjohann D, Diczfalusy U, Ståhle L, Ahlborg G, Wahren J. Cholesterol homeostasis in human brain: turnover of 24S-hydroxycholesterol and evidence for a cerebral origin of most of this oxysterol in the circulation. J Lipid Res. 1998;39:1594-600.

182. Bretillon L, Lütjohann D, Ståhle L, Widhe T, Bindl L, Eggertsen G, et al. Plasma levels of 24S-hydroxycholesterol reflect the balance between cerebral production and hepatic metabolism and are inversely related to body surface. J Lipid Res. 2000;41:840-5.

183. Kim WS, Chan SL, Hill AF, Guillemin GJ, Garner B. Impact of 27-hydroxycholesterol on amyloid-beta peptide production and ATP-binding cassette transporter expression in primary human neurons. J Alzheimers Dis. 2009;16:121-31.

184. Moutinho M, Nunes MJ, Gomes AQ Gama MJ, Cedazo-Minguez A, Rodrigues CM, et al. Cholesterol 24S-hydroxylase overexpression inhibits the liver $\mathrm{X}$ receptor (LXR) pathway by activating small guanosine triphosphate-binding proteins (sGTPases) in neuronal cells. Mol Neurobiol. 2015;51:1489-503.

185. Noguchi N, Saito Y, Urano Y. Diverse functions of 24(S)-hydroxycholesterol in the brain. Biochem Biophys Res Commun. 2014;446:692-6.

186. Brown AJ, Sharpe LJ, Rogers MJ. Oxysterols: from physiological tuners to pharmacological opportunities. Br J Pharmacol. 2021;178:3089-103.

187. Qi X, Liu H, Thompson B, McDonald J, Zhang C, Li X. Cryo-EM structure of oxysterol-bound human Smoothened coupled to a heterotrimeric $\mathrm{G}_{\mathrm{i}}$. Nature. 2019;571:279-83.

188. Zhornitsky S, McKay KA, Metz LM, Teunissen CE, Rangachari M. Cholesterol and markers of cholesterol turnover in multiple sclerosis: relationship with disease outcomes. Mult Scler Relat Disord. 2016;5:53-65.

189. Han M, Wang S, Yang N, Wang X, Zhao W, Saed HS, et al. Therapeutic implications of altered cholesterol homeostasis mediated by loss of CYP46A1 in human glioblastoma. EMBO Mol Med. 2020;12:e10924.

190. Wang Y, Muneton S, Sjövall J, Jovanovic JN, Griffiths WJ. The effect of 24S-hydroxycholesterol on cholesterol homeostasis in neurons: quantitative changes to the cortical neuron proteome. J Proteome Res. 2008;7:1606-14.

191. Gamba P, Giannelli S, Staurenghi E, Testa G, Sottero B, Biasi F, et al. The controversial role of 24-S-hydroxycholesterol in Alzheimer's disease. Antioxidants (Basel). 2021;10:740. 
192. Sodero A0. 24S-hydroxycholesterol: cellular effects and variations in brain diseases. J Neurochem. 2021;157:899-918.

193. Yamanaka K, Saito Y, Yamamori T, Urano Y, Noguchi N. 24(S)-hydroxycholesterol induces neuronal cell death through necroptosis, a form of programmed necrosis. J Biol Chem. 2011;286:24666-73.

194. Zarrouk A, Hammami M, Moreau T, Lizard G. Accumulation of 24S-hydroxycholesterol in neuronal SK-N-BE cells treated with hexacosanoic acid (C26:0): argument in favor of 24S-hydroxycholesterol as a potential biomarker of neurolipotoxicity. Rev Neurol (Paris). 2015;171:125-9.

195. Björkhem I, Leoni V, Svenningsson P. On the fluxes of side-chain oxidized oxysterols across blood-brain and blood-CSF barriers and origin of these steroids in CSF (review). J Steroid Biochem Mol Biol. 2019;188:86-9.

196. Heverin M, Meaney S, Lütjohann D, Diczfalusy U, Wahren J, Björkhem I. Crossing the barrier: net flux of 27-hydroxycholesterol into the human brain. J Lipid Res. 2005;46:1047-52.

197. Zhang DD, Yu HL, Ma WW, Liu QR, Han J, Wang H, et al. 27-Hydroxycholesterol contributes to disruptive effects on learning and memory by modulating cholesterol metabolism in the rat brain. Neuroscience. 2015;300:163-73.

198. Spencer TA, Gayen AK, Phirwa S, Nelson JA, Taylor FR, Kandutsch AA, et al. 24(S),25-Epoxycholesterol. Evidence consistent with a role in the regulation of hepatic cholesterogenesis. J Biol Chem. 1985;260:13391-4.

199. Goyal S, Xiao Y, Porter NA, Xu L, Guengerich FP. Oxidation of 7-dehydrocholesterol and desmosterol by human cytochrome P450 46A1. J Lipid Res. 2014;55:1933-43.

200. Wong J, Quinn CM, Guillemin G, Brown AJ. Primary human astrocytes produce 24(S),25-epoxycholesterol with implications for brain cholesterol homeostasis. J Neurochem. 2007;103:1764-73.

201. Meljon A, Theofilopoulos S, Shackleton CHL, Watson GL, Javitt NB, Knölker HJ, et al. Analysis of bioactive oxysterols in newborn mouse brain by LC/MS. J Lipid Res. 2012;53:2469-83.

202. Hubler Z, Friedrich RM, Sax JL, Allimuthu D, Gao F, Rivera-León AM, et al. Modulation of lanosterol synthase drives 24,25-epoxysterol synthesis and oligodendrocyte formation. Cell Chem Biol. 2021;28:866-75.e5.

203. Theofilopoulos S, Abreu de Oliveira WA, Yang S, Yutuc E, Saeed A, Abdel-Khalik J, et al. 24(S),25-Epoxycholesterol and cholesterol 24S-hydroxylase (CYP46A1) overexpression promote midbrain dopaminergic neurogenesis in vivo. J Biol Chem. 2019;294:4169-76.

204. Roeper J. Dissecting the diversity of midbrain dopamine neurons. Trends Neurosci. 2013;36:336-42.

205. Luo J, Yang H, Song BL. Mechanisms and regulation of cholesterol homeostasis. Nat Rev Mol Cell Biol. 2020;21:225-45.

206. Jin U, Park SJ, Park SM. Cholesterol metabolism in the brain and its association with Parkinson's disease. Exp Neurobiol. 2019;28:554-67.

207. Petrov AM, Kasimov MR, Zefirov AL. Brain cholesterol metabolism and its defects: linkage to neurodegenerative diseases and synaptic dysfunction. Acta Naturae. 2016;8:58-73. 